\title{
Revista de la
}

CEPAL

\author{
Director \\ RAUL PREBISCH
}

Secretario Técnico

ADOLFO GURRIERI

Secretario Adjunto

GREGORIO WEINBERG

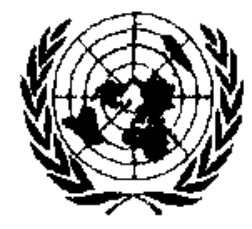

NACIONES UNIDAS

COMISION ECONOMICA PARA AMERICA LATINA

SANTIAGO DE CHILE / ABRIL DE 1982 


\section{Revista de la \\ C E P A L}

Número $16 \quad$ Santiago de Chile

Abril 1982

\section{S U M A R I O}

Agricultura y Alimentación. Evolución y transformaciones más recientes en América Latina. Luis López Cordovez.

La agricultura latinoamericana. Perspectivas hasta fines de siglo. Nurul Islam.

Capitalismo y población en el agro latinoamericano. Tendencias y problemas recientes. Carmen A. Miró y Daniel Rodríguez.

La agricultura campesina en América Latina. Situaciones y tendencias. Emiliano Ortega.

Principales enfoques sobre la economía campesina. Klous Heynig

El campesinado en América Latina. Una aproximación teórica. Raúl Brignol y Jaime Crispi.

Clase y cultura en la transformación del campesinado.

John Durston.

Notas y comentarios:

Exposición de Kenneth Dadzie en la ceremonia inaugural

del decimonoveno período de sesiones de la CEPAL.

Algunas publicaciones de la CEPAL.

Indice de los primeros quince números de la Revista de la CEPAL 
REVISTA DE LA CEPAL

Abril de 1982

\section{Agricultura y alimentación}

\section{Evolución}

$\mathrm{y}$ transformaciones

más recientes

\section{en América Latina}

\section{Luis López Cordovez*}

En este trabajo se examinan los principales aspectos de la evolución y de las transformaciones recientes de la agricultura y alimentación de los paises latinoamericanos, y se pretende además ofrecer una apretada visión de conjunto, a pesar de las limitaciones derivadas de información insuficiente $y$ a veces parcial.

Para el análisis efectuado se han tenido en cuenta algunos aspectos relevantes del nuevo marco agricola mundial que influyeron en grado diverso en el comportamiento de las agriculturas nacionales.

La agricultura regional presenta una combinación de progresos resultantes del aprovechamiento - a veces parcial- de sus potencialidades y de problemas no resueltos, que podrian estarse agravando. De todos modos, el progreso económico es evidente, ya que sus dimensiones aumentaron en 1.4 veces durante la década de los años setenta. Su avance técnico es notorio y al mismo tiempo diferenciado. Ambos se han sustentado tanto en los estimulos derivados de las políticas públicas como de condiciones atractivas -aunque selectivasde mercados en expansión. La formación acelerada de capital en las unidades productivas empresariales hizo posible gran parte de la expansión productiva lograda. La coexistencia de ese progreso material junto a la persistencia de la pobreza nural constituye el rasgo negativo más notable del agro latinoamericano.

* Director de la División Agricola Comjunta CEPAL/FAO.

\section{I \\ La agricultura en el contexto global*}

La diversidad de situaciones que presentan actualmente las agriculturas nacionales dificulta una apreciación de alcance regional. Pese a las dificultades derivadas de la creciente heterogeneidad que determina diferencias importantes en el significado de la actividad agrícola dentro de la economía global, en su orientación productiva, en su vinculación con los mercados internos y externos, en las dimensiones, características, dinamismo y conducta económica de los segmentos que la conforman, en las relaciones de esos segmentos entre sí y con el resto del sistema económico, hay suficientes elementos comunes que permiten configurar una visión de conjunto de la región que ilustre sobre el rumbo e intensidad de las transformaciones económicas y sociales que viene experimentando el agro latinoamericano.

Durante los decenios pasados, por sus dimensiones y recursos propios, la agricultura era un sector de relevante importancia en la mayoría de las economías nacionales, mientras que la industria se encontraba en etapas relativamente incipientes de su desarrollo. Por lo tanto, y escasos como eran entonces los recursos de capital - salvo en los países con elevadas exportaciones de minerales o petróleo-y reducida la asistencia financiera externa, el agro debía contribuir al crecimiento de otras actividades económicas. A esta situación se sumaba el generalizado convencimiento de que la expansión de la agricultura podría lograrse haciendo uso más eficaz de los recursos ya aplicados al sector, puesto que sus propias necesidades de capital eran más bien modestas.

La industria ha sido, sin lugar a dudas, el sector de mayor dinamismo en el desarrollo del sistema económico latinoamericano. La agricultura, por su parte, desempeñó una función notable: contribuyó de modo importante a ese dinamismo del sector industrial. Continúa desempeñando el mismo papel, pero a pesar de

*El autor agradece las valiosas observaciones y sugerencias de los señores Emiliano Ortega y Rolando Chateatneuf. 
que sus dimensiones económicas son bastante mayores que las que tuvo en los decenios anteriores, ya no ocupa el lugar destacado de entonces, como sector cuyo excedente económico podria ser transferible al resto del sistema económico.

A comienzos de los años ochenta, en algunos países la agricultura tiene gran relevancia, en cambio en otros ocupa una posición más discreta. Entre 1970 y 1980 , a nivel regional y según las cuentas nacionales, el producto interno bruto agrícola crecí al $3.5 \%$ por año, frente a] $5.6 \%$ registrado por el producto interno bruto total. La participación de la agricultura en el producto total bajó, en el mismo período, del $14 \%$ al $11.4 \%$. Por su parte, la fuerza de trabajo agrícola respecto a la total disminuyó durante el decenio del 42.1 al $36.2 \% .^{1}$ Desde luego, tanto las tasas de incremento del producto agrícola como su participación en el producto total y las dimensiones de la población agrícola respecto a la población total, varían bastante de un país a otro.

Cuando se transforma y diversifica la economía, la agricultura reduce de manera progresiva su peso relativo respecto al total, lo cual induce por lo general a enjuiciar equivocadamente el comportamiento del sector y calificarlo de modo negativo. Dentro del proceso de desarrollo económico es normal que disminuya la contribución de la agricultura, medida por los indicadores macroeconómicos globales que pueden desagregarse a nivel sectorial. Esa mengua por sí misma no implica una manifestación de dinamismo insuficiente. La naturaleza y magnitud de la evolución agricola debe ser examinada no sólo a através de indicadores estadísticos sobre producción y productividad, sino también de otros que reflejen transformaciones socioeconómicas derivadas de cambios en la distribución del ingreso, en las dimensiones de la pobreza extrema y en el grado de ocupación de la fuerza de trabajo.

En la década de los años setenta se comprobó que la mayoría de las agriculturas nacionales, desde hace algún tiempo y con intensidad y profundidad distintas, habían venido experimentando transformaciones sustantivas en

1 CEPAL, "Proyecciones del desarrollo latinoamerica" no en los años cochenta" (E/CEPAL/G.1158), abril de L,981. sus estructuras socioeconómicas y en las relaciones existentes entre ellas. Se analizó y demostró que la modernización tecnológica de la agricultura no era un hecho aislado, sino que formaba parte de un conjunto de hechos que evidenciaba su carácter integrado e interdependiente respecto al desarrollo de los demás sectores económicos. Dicho conjunto de vinculaciones y repercusiones se extiende y entrelaza con el sistema de relaciones externas de las economías nacionales. ${ }^{2}$

La integración e interdependencia de la agricultura con el desarrollo global es, por lo tanto, determinante de los cambios que en su seno se vienen observando; para entender acabadamente lo acaecido en el agro tanto en lo productivo como en su estratificación social, se debe prestar particular atención a las relaciones intersectoriales, las que ayudan a explicar lo ocurrido a la luz de situaciones y procesos más amplios y complejos que los ligados sólo a las variables propias del sector agrícola.

Dentro de ese marco de integración e interdependencia se ha tornado cada vez más difícil que los propósitos - generales para toda la agricultura, específicos para cada línea de producción o en beneficio del amplio mundo campesino-perseguidos por el Estado a través de sus programas y acciones prioritarias, sean plenamente compatibles y coherentes entre sí y entre ellos y los objetivos postulados para el sistema económico en su conjunto. Las dificultades, inconsistencias y contradicciones fueron mayores cuando los paises tuvieron que encarar opciones, revisar metas y objetivos y aplicar políticas de ajuste interno para hacer frente a la coyuntura externa.

El ingreso medio de la población que depende de la agricultura sigue siendo bastante más bajo que el de la población no agrícola. La evolución de la agricultura, a pesar de los progresos productivos alcanzados - que se describen más adelante-, aún no satisface las exigencias que en lo económico y social tiene sobre esta actividad el desarrollo de la economía y sociedad latinoamericanas.

\footnotetext{
2CEPAL y FAO, "Desarrollo social rural en América Latina" (CEPAL/FAO/78/2), Heunión Técnica CEPAL FAO sobre desarrollo social rural en América Latina, Montevideo, Uruguay, 9-11 de agosto de 1978.
} 


\section{II}

\section{La producción agrícola regional en los años setenta}

Las acentuadas alteraciones e incertidumbres de alcance mundial ocurridas en los ámbitos económico, social y político durante la década pasada, y de modo más evidente durunte su segunda mitad, afectaron intensamente los mercados agrícolas internacionales -de productos, de insumos tecnológicos y financieros-, y a través de ellos repercutieron de modo y profundidad diversos sobre el proceso productivo agrícola de los países desarrollados y en desarrollo.

América Latina no escapó a esas repercusiones. Cuando la fracción exportada de un producto supera un tercio del total regional producido, es notoria la incidencia de las condiciones de los mercados extemos sobre el proceso de prođucción; por ello, antes de entrar en el examen de lo ocurrido con la producción agrícola regional, se presenta un breve esbozo de la agricultura mundial.

\section{Algunos aspectos relevantes del nuevo marco agrícola mundial}

El período comprendido entre el comienzo de los años cincuenta y setenta fue, en general, de crecimiento definido y estable de la producción agrícola mundial y, en particular, de la de alimentos, acompañada ésta por un crecimiento sin precedentes del consumo alimentario. El principal problema que en $1970 / 1971$ se le planté a la agricultura mundial fue la forma de conciliar la necesidad de aumentar los ingresos obtenidos de las exportaciones de productos agrícolas, con la de mejorar los ingresos de los productores agrícolas tanto de países desarrollados como en desarrollo y de conservar, al mismo tiempo, una mayor estabilidad y firmeza en los mercados intemacionales y con ello un mejor equilibrio entre la oferta y la demanda a nivel mundial.

De acuerdo a cifras de la $\mathrm{FAO}^{3}$ se concluye

\footnotetext{
años.
}

que el valor de la producción agrícola mundial creció al $2.9 \%$ anual entre 1950 y 1972 , en tanto que el valor del comercio internacional de productos agrícolas lo habría hecho al $5.0 \%$ por año. El período se caracterizó por aumento de la dependencia alimentaria de las regiones en desarrollo respecto a las importaciones. En 1972, debido a la coincidencia de grandes déficit productivos en varios productos intexrelacionados, creció sustancialmente la demanda internacional y por ello se debió recurrir copiosamente a las reservas para subsanar gran parte del desnivel entre la demanda y la oferta. Cuando en 1973 las reservas rayaban en sus niveles más bajos, se produjo un alza pronunciada de los precios. El fuerte aumento de los precios del petróleo y los trastornos financieros y monetarios resultantes, afectaron los balances de pagos, aceleraron la inflación y estimularon la especulación, introduciendo incertidumbres adicionales que generaron situaciones muy tensas entre oferta y demanda en los mercados agrícolas internacionales.

El alza de los precios de los fertilizantes, plaguicidas, combustibles y lubricantes impulso ajustes en los sistemas de producción, en particular en lo relativo a la localización y composición de los cultivos y selección de procesos técnicos que implicasen ahorro de energía.

En 1975/1976 se inició la recuperación económica de los países industrializados, bajaron los precios agrícolas internacionales y se acumularon existencias en los países importadores. ${ }^{4}$ En 1977 aumentaron la producción y los suministros agrícolas mundiales, lo que coincidió con la recuperación de la demanda al elevarse los ingresos de los consumidores e incluso se registró una cierta recuperación de las existencias. Al recobrarse la demanda en 1978 subieron ligeramente los precios, lo que coincidi 6 con un aumento considerable de los precios de las exportaciones de manufacturas, empeo-

${ }^{4} \mathrm{FAO}$, Situación y perspectivas de los productos básicos, 1975-1976, Roma, 1976. 
rando la relación de los términos del intercambio. Después de dos años de expansión sustancial de la producción -1977 y 1978--, ésta cayó en 1979, llegando a invertirse la tendencia, lo que a su vez generó una nueva alza de los precios. ${ }^{5}$ En 1980, la producción mundial creció ligeramente, pero en términos de produccion por habitante disminuyó por segundo año consecutivo. Los precios internacionales de los fertilizantes subieron entre 20 y $30 \%$ respecto a sus niveles de 1979, lo que contribuyó a un nuevo incremento de los precios agrícolas a comienzos de $1981 .{ }^{6}$

La FAO seleccionó 21 productos que representaban alrededor del $50 \%$ del comercio agrícola mundial para apreciar el grado de inestabilidad, entre 1968 y 1978 , de los precios y del volumen en el comercio internacional (véase el cuadro 1); y encontró como particularidad más significativa el importante y generalizado aumento de la inestabilidad de los precios a mediados de los años setenta, en comparación con los últimos años del decenio de los años sesenta y con los primeros de la década siguiente. La variabilidad del volumen de las exportaciones acusó pocos cambios. En el período 1974-1978 hubo una significativa tendencia generalizada hacia una estabilidad ligeramente mayor. $^{7}$

Son numerosas, complejas y variables las causas de la notoria desestabilización de tan amplia gama de precios de productos agricolas. Parece, sin embargo, que dentro de ellas han desempeñado un papel subordinado las variac ciones del volumen de producción o de las exportaciones; tampoco parece haberse producido una mayor inelasticidad de los precios. Entre 1974 y 1978 han adquirido mayor importancia los cambios en las estructuras de comercialización, el empequeñecimiento de los mercados mundiales residuales debido a mayor autosuficiencia de países importadores y la mayor protección ofrecida a los productores nacionales. La aceleración de la inflación mundial y el aumento de la inestabilidad de los mercados

\footnotetext{
${ }^{5}$ bídem, 1979-1980.

${ }^{6} \mathrm{FAO}$, El estado mundial de la agricultura y la alimentación. 1980, Roma, mayo de 1981 .

${ }_{7}$ FAO, Siluación y perspectivas de los productos básicos, 1979-1980, Roma, 1980.
}

monetarios mundiales son factores que posibilitaron una mayor actividad en los intercambios mundiales de productos agrícolas y contribuyeron a una mayor variabilidad de sus precios."

Entre 1970 y 1978 el valor de las exportaciones agrícolas mundiales habría crecido al $18.3 \%$ anual a precios corrientes y al $4,4 \%$ anual a precios reales, en tanto que la producción mundial creció al $2.5 \%$ anual. ${ }^{g}$ En el período de referencia, Estados Unidos mantuvo su condición de primer exportador mundial de granos y semillas oleaginosas. Estas exportaciones junto a las de productos pecuarios y otros no alimenticios, como algodón y tabaco, determinaron que las exportaciones agrícolas norteamericanas crecieran al $9 \%$ anual entre 1972 y 1980 , frente al $5.5 \%$ por año registrado durante el período $1950-1972 .{ }^{10}$

La producción norteamericana de cereales y granos oleaginosos pasó de 147 a alrededor de 350 millones de toneladas entre 1950 y 1980. A partir de 1973 entraron en producción los 65 millones de acres de tierras antes no utilizadas. Dentro de los principales países productores y exportadores, Estados Unidos mostró poseer mayor capacidad de producción y de ajuste de sus políticas frente a las cambiantes situaciones de los mercados internacionales; elevó su grado de competitividad en dichos mercados al mismo tiempo que aumentó su producción al ritmo de la expansión de la demanda mundial. A comienzos de los años ochenta, Norteamérica había puesto en producción para la exportación prácticamente toda su capacidad de tierras habilitadas, incluyendo aquellas que durante más de dos décadas estuvieron fuera de cultivo."

Además de haberse volcado con mayor intensidad a los mercados internacionales, la agricultura norteamericana logró eliminar la fuerza de trabajo redundante; el desequilibrio crónico entre tierra y fuerza de trabajo, que se extendió hasta comienzo de los años setenta, dejó de ser un problema insoluble.

La lenta migración a las ciudades, la resi-

\footnotetext{
Stbidem.

9 thidem.

L"United States Department of Agriculture, Agriculiural-food Policy Review, Washingtom, abril de 1981.

II United States Department of Agriculture, op. cit.
} 
Cuadro 1

\section{MUNDO: VARIACION EN LOS PRECIOS DE EXPORTACION Y EN LAS CANTIDADES EXPORTADAS DE LOS PRODUCTOS INDICADOS, 1968-1979 Y 1974-1978}

(En porcentajes)

\begin{tabular}{|c|c|c|c|c|c|c|}
\hline & \multicolumn{2}{|c|}{$1968-1972$} & \multicolumn{2}{|c|}{$1974-1978$} & \multicolumn{2}{|c|}{$\begin{array}{c}\text { Relación 1974-1978, } \\
1968-1979\end{array}$} \\
\hline & Precio & Cantidad & Precio & Cantidad & Precio & Cantidad \\
\hline Café & 9.16 & 11.09 & 34.97 & 17.18 & 3.82 & 1.55 \\
\hline Té & 5.56 & 13.42 & 24.48 & 20.47 & 4.40 & 1.53 \\
\hline Azúcar & 19.19 & 18.27 & 44.14 & 16.89 & 2.30 & 0.92 \\
\hline Trìgo & 8.26 & 17.28 & 11.70 & 10.01 & 1.42 & 0.58 \\
\hline Arroz & 10.04 & 13.55 & 22.89 & 14.84 & 2.28 & 1.10 \\
\hline Maíz & 8.22 & 17.47 & 12.29 & 12.93 & 1.50 & 0.74 \\
\hline Cebada & 6.75 & 20.94 & 7.01 & 11.88 & 1.04 & 0,57 \\
\hline Mantequilla & 25.81 & 26.54 & 5.62 & 12,31 & 0.22 & 0.46 \\
\hline Queso & 23.26 & 8.57 & 6.15 & 9.12 & 0.26 & 1.06 \\
\hline Soja & 5.09 & 24.93 & 38.18 & 22.38 & 7.50 & 0.90 \\
\hline Aceite de soja & 13.75 & 21.76 & 23.19 & 22.51 & 1.69 & 1.03 \\
\hline Aceite de semilla de algodón & 14.88 & 43.34 & 18.64 & 26.12 & 1.25 & 0.60 \\
\hline Aceite de oliva & 9.42 & 21.59 & 4.94 & 29.30 & 0.52 & 1.36 \\
\hline Aceite de palma & 15.60 & 15.26 & 22.25 & 15.81 & 1,43 & 1.04 \\
\hline Caucho & 13.07 & 6.16 & 16.61 & 7.00 & 1.27 & 1.14 \\
\hline Algodón & $\mathbf{5 . 6 5}$ & 18.73 & 14.15 & 12.64 & 2.50 & 0.67 \\
\hline Cacao & 19.51 & 8.34 & 25.43 & 8.66 & 1,30 & 1.04 \\
\hline
\end{tabular}

Fuente: FAO, Situación y perspectivas de los productos bésicox, 1979-1980. Roma, 1980.

La FAO calculó los coeficientes de variación partiendo de datos trimestrales sobre precios y cantidades de exportación, que ajusto para tener en cuenta las tendeneias.

dencia en el campo no asociada con el empleo en la agricultura, la plena utilización de la tierra disponible, una corriente de innovaciones tecnológicas que además de liberar mano de obra permitió que la producción creciese tan rápido como la demanda interna y en particular la externa, y el logro de una mejor relación entre productividad agrícola y no agricola - debido a que la tasa de retorno creció apreciablemente en los años setenta-son factores que, en conjunto, condujeron a la desaparición del clásico desequilibrio tierra-hombre..2

Los problemas que concentran la atención en la toma de decisiones sobre la política agrícola norteamericana, al contrario de lo que ocurrió en el pasado, no se vinculan con el manejo de una excesiva capacidad de producción, sino con la introducción de ajustes en la

\footnotetext{
${ }^{12}$ Ibidem.
}

producción para evitar escasez, particularmente en cereales y oleaginosas. Estados Unidos suministra casi la mitad del volumen transado en los mercados internacionales de esos productos, por lo tanto, las fluctuaciones de la demanda y produccion mundiales de esos productos repercuten de modo ampliado en las decisiones norteamericanas de producción anual. La expansión de la demanda internacional por productos agrícolas de Estados Unidos se triplicó en los años setenta; y es evidente que continuará creciendo durante esta década.

Desde 1973, la inestabilidad monetaria repercutió seriamente sobre la agricultura de la CEE, lo que condujo a la adopción de medidas complejas y al establecímiento de compensaciones monetarias, para evitar la desintegración del mercado agrícola común, de modo que la tarea de fijar los precios agrícolas anuales -dentro del ámbito económico global- 
fue una de las mayores dificultades que enfrentó la Comunidad.

En los años setenta, la agricultura de la CEE soportó ajustes estructurales acompañados por progresos técnicos. Creció rápidamente el tamaño de las unidades agrícolas y se redujo el número de productores; como resultado de ello mejoró la productividad y aumentó en forma sostenida el volumen anual de prácticamente todos los productos. El consumo no siempre creció al mismo ritmo; en algunos productos lo hizo con la misma velocidad que la producción, en otros aumentó basado en una elevada intervención del gasto público agrícola -productos lácteos-, y finalmente en otros donde se constituyeron o mantuvieron excedentes -carne, azúcar y productos lácteos-., se estimularon las exportaciones mediante programas específicos muy activos, junto a costosas medidas para incentivar de diversas formas el consumo interno.

Entre 1978 y 1980, el comercio agrícola intracomunitario mostró tendencia al estancamiento en la mayoría de los productos - cereales y carne en particular-, lo que contrasta con los considerables incrementos registrados en el período 1973-1978 luego de la incorporación de Inglaterra, Dinamarca e Irlanda a la CEE. ${ }^{13}$ Esto indica que la Comunidad depende cada vez más de las exportaciones a terceros países para disponer de algunos de sus excedentes. Las exportaciones de azúcar y productos lácteos se beneficiaron por las caídas de la producción de los principales países productores -por condiciones climáticas adversas o por objetivos de política-, lo que determinó una reducción de los suministros y elevados precios en los mercados mundiales.

El principal problema que enfrenta la CEE a corto y a mediano plazo consiste en determinar cómo podrá disponer de sus crecientes volúmenes de producción, tanto interna como externamente y a precios razonables, que salvaguarden el ingreso de los productores y que al mismo tiempo se mantengan dentro de los límites de intervención estatal defi-

\footnotetext{
13 Commission of the European Communities, The agricultural situation in the Community, 1980 Report, Brtiselas, diciembre de 1980 .
}

nidos por las magnitudes de los fondos públicos al efecto asignados.

La CEE ocupa el segundo lugar como exportador mundial de productos agrícolas (10\% del total mundial) precedida por Estados Unidos (alrededor de $20 \%$ ) y seguida por Canadá (7\%). La participación de la CEE en el total mundial ha permanecido relativamente estable a largo plazo. Cayeron ligeramente sus exportaciones en el período 1973-1976, pero entre 1976 y 1979 se recuperaron. En 1978 , el $48 \%$ de las exportaciones agrícolas de la CEE fue a paises industrializados, un $43 \%$ a países en desarrollo y $9 \%$ a países de economías centralmente planificada. $Y$ alrededor de dos tercios de sus exportaciones consistieron en productos procesados. ${ }^{14}$ Llama la atención el caso de los elaborados de café, té y cacao, que la CEE no cultiva y exporta en elevados volúmenes, basados en importaciones de productos primarios procedentes de países en desarrollo.

Dos años de cosechas mundiales insatisfactorias - 1979 y 1980 - condujeron al empeoramiento de la situación alimentaria mundial. Puesto que la cosecha de 1981 fue bastante mejor que la esperada, la amenaza de una nueva crisis alimentaria de vastas proporciones parece haberse alejado. Pero a consecuencia de la mengua de la producción cerealera en 1980 , aumentaron sensiblemente las necesidades de importación. La FAO ${ }^{15}$ estimó que en 1980/ 1981 los países en desarrollo habrán importado 95 millones de toneladas de cereales, cifra que representa un $7 \%$ más que durante el bienio precedente. La demanda aumentó cuando la restricción de las disponibilidades había provocado un alza neta de los precios. Como a su vez los fletes marítimos también se incrementaron, el costo de las importaciones alimentarias aumentó seriamente.

\section{El comportamiento productivo regional}

Para varios países latinoamericanos, la expansión del mercado interno fue determinando de modo decisivo el comportamiento de su pro-

\footnotetext{
lithidem

${ }^{15}$ FAO, Sistema mundial de información y alerta sobre la atimentación y la agricultura: perspectivas alimentarias, Roma, varios números correspondientes a 1981 .
} 
ducción agrícola y su composición; para ótros su agricultura ha continuado internacionalizándose. En ambos casos, las agriculturas nacionales han sido afectadas no sólo por las repercusiones de requerimientos por mayores volúmenes producidos, sino además por las características y composición de los mercados de los cuales dependen básicamente.

Consideradas las agriculturas nacionales por sus dimensiones -medidas por su producto interno bruto agrícola a precios de $1970^{16}$ se tiene que en el trienio 1970-1972, la agricultura mexicana era la de mayor magnitud, y le seguían la brasileña, argentina, colombiana, peruana y venezolana, para citar en orden decreciente a las más importantes. Al término de la década -trienio 1978/1980-el primer lugar lo ocupa Brasil, seguido por México y Argentina que supera ligeramente a Colombia, a la que sigue Penú, casi alcanzado por Venezuela.

Cuatro países -Paraguay, Brasil, Guatemala y Colombia- alcanzaron en los años setenta aumentos medios de su PIB agrícola superiores al $4 \%$ anual. Cinco - Nicaragua, Venezuela, Ecuador, República Dominicana y Argentina - lograron un crecimiento agrícola entre 3 y $4 \%$ por año. Cuatro países - Bolivia, El Salvador, Costa Rica y México- tuvieron un incremento anual entre 2 y $3 \%$. En otros seis -Chile, Haití, Panamá, Honduras, Uruguay y Perí- el aumento anual medio fue inferior al $2 \%$.

El análisis de la evolución productiva a través del crecimiento del producto interno bruto sectorial, según cuentas nacionales, adolece de varias limitaciones, entre las cuales se destaca la imposibilidad de explicar lo ocurrido con las diferentes líneas de producción y la dificultad para identificar y ponderar las causas que han determinado su dinamismo o estancamiento. Por ello, se examina a continuación el comportamiento productivo de la agricultura en función del volumen físico por productos. Este ha sido dinámico (3.3\% por año en términos del valor bruto de la producción) comparado con el obtenido por el conjunto de las regiones en desarrollo ( $2.9 \%$ anual) y por los países desarro-

${ }^{16}$ CEPAL, "Proyecciones del desarrollo latinoamericano en los años ochenta" (E/CEPAL/G.1158), abril de 1981. llados, $2 \%$ por año. Examinado, según el valor bruto de la producción por habitante latinoamericano, cabe calificarlo como relativamente dinámico; alcanzó al $0.8 \%$ por año. Sin embargo, es insuficiente respecto a la demanda potencial de alimentos de la sociedad latinoamericana, que incluye alrededor de 45 millones de malnutridos; ha crecido menos que la demanda efectiva, ya que ésta lo habría hecho al $3.6 \%$ por año. Es insuficiente, también, respecto al potencial productivo agrícola latinoamericano; pues se utiliza algo más de una cuarta parte de la superficie cultivable. Es insuficiente, además, frente a los requerimientos de exportación agrícola de los países latinoamericanos para sanear sus balances comerciales y de pagos y para reducir su endeudamiento externo. Por último es insuficiente respecto a la intensidad de crecimiento productivo, necesario como base material indispensable para elevar la calidad de vida en el medio rural.

El comportamiento productivo ha sido diferenciado. Los cultivos crecieron más lentamente que los pecuarios; lo hicieron al 3.1 y $3.7 \%$ por año, respectivamente. Esa tendencia sè insinuó en los años sesenta y en ella influyeron numerosos y complejos factores. Cabe destacar nuevamente aquí la incidencia de condiciones climáticas desfavorables sobre el volumen y composición anual de la producción.

La evolución por líneas de producción muestra marcadas diferencias entre grupos de productos; algunas fueron dinámicas, otras de crecimiento lento $y$ algunas registraron reducciones. Cuatro grupos de productos vegetales crecieron más aceleradamente que la población: oleaginosas, hortalizas, frutas y sacarinos. Dentro de los pecuarios lo hicieron la carne de aves y de cerdo, los huevos y la leche. Los cereales, las bebidas estimulantes, las leguminosas secas y la carne bovina crecieron ligeramente menos que la población. Por último, declinó la producción en las raíces y tubéxculos y en las fibras vegetales, excluido el algođón. El cuadro 2 muestra lo ocurrido con cada grupo de productos y con los principales productos por separado.

Entre los cultivos, el grupo más dinámico es el de las oleaginosas y a su vez dentro de éste destaca la soja. El espectacular aumento de las oleaginosas se explica principalmente por la 
expansión del área cosechada, la qque aportó el $68 \%$ del aumento de la producción. De todos modos, no se debe subestimar el aumento de los rendimientos que crecieron al $2.8 \%$ por año, tasa que duplica el crecimiento de los rendimientos medios de los cultivos.

Guadro 2

\section{AMERICA LATINA: PRODUCCION, AREA COSECHADA Y RENDIMIENTOS MEDIOS FISICOS, 1969-1971 A 1978-1980}

(Tasas anuales de crecimiento, porcentajes)

\begin{tabular}{|c|c|c|c|}
\hline Cultivos & $\begin{array}{l}\text { Volumen } \\
\text { producido }\end{array}$ & $\begin{array}{c}\text { Area } \\
\text { cosechada }\end{array}$ & $\begin{array}{l}\text { Rendimientos } \\
\text { físicos }\end{array}$ \\
\hline Cereales & 2.4 & 0.7 & 1.6 \\
\hline Trigo & 2.6 & 1.5 & 1.1 \\
\hline Arroz & 3.4 & 2.1 & 1,2 \\
\hline Maiz & 1,3 & -0.1 & 1.4 \\
\hline Sorgo & 5.5 & 2.6 & 2.8 \\
\hline Ratces y tuberculos & -0.7 & 0.3 & -1.0 \\
\hline Papas & 1.4 & -0.3 & 1.7 \\
\hline Mandioca & -1.1 & 0.7 & -1.8 \\
\hline Caña de azúcar & 3.5 & 2.3 & I.I \\
\hline Leguminosas secas & 0.7 & 1.1 & -0.5 \\
\hline Frejol & 0.5 & 1.3 & -0.7 \\
\hline Oleaginosas & 14.2 & 11.1 & 2.8 \\
\hline Soja & 25.9 & 23,6 & 1.9 \\
\hline Hortalizas & 3.2 & 2.1 & 1.1 \\
\hline Erutas & 3.5 & 0.3 & 3.2 \\
\hline Banano & 1.9 & 0.3 & 1.3 \\
\hline Cítricos & 7.5 & $\ldots$ & $\ldots$ \\
\hline Manzanas & 7.1 & $\ldots$ & $\ldots$ \\
\hline Bebidas y tabaco & 2.5 & 0.9 & I.6 \\
\hline Cacao & 4.2 & 0.5 & 3.6 \\
\hline Café & 1.9 & 0.8 & 1.0 \\
\hline Tabaco & 4.1 & 2.3 & 1.7 \\
\hline Algodón en rama & 1.4 & 0.5 & 0.9 \\
\hline Fibras vegetales & -1.4 & -0.2 & -1.2 \\
\hline Otros cultivos & 5.0 & 4.0 & 10 \\
\hline Total cultivos & 3.1 & 1.7 & 1.4 \\
\hline Pecuarios & $\begin{array}{l}\text { Volumen } \\
\text { producido }\end{array}$ & & $\begin{array}{l}\text { Animales faenados } \\
\text { o en producción a/ }\end{array}$ \\
\hline Carnes & 3.3 & & \\
\hline Bovina & 2.1 & & $2.0 \mathrm{~b}$ \\
\hline Porcina & 3.4 & & $3.3 \mathrm{~b}$ \\
\hline Aves & 9.3 & & $9.3 \mathrm{~b}$ \\
\hline Otros pecuarios & 3.3 & & \\
\hline Leche ${ }^{c}$ & 3.2 & & $2.6 \mathrm{c}$ \\
\hline Huevos d & 5.1 & & $4,5 \mathrm{~d}$ \\
\hline Total pecuarios & 3.6 & & 2.6 \\
\hline Total agropecuarios & 3.3 & & \\
\hline
\end{tabular}

Fuente: Elaborado por la División Agricola Conjunta CEPAL/FAO, a base de cifras de la FAO.

alnclujdas mejoras en los rendimientos fisicos.

b'Total animales faenados.

vacas lechando.

dTotal gallinas ponedoras 
Tanto la demanda interna como las exportaciones de oleaginosas han crecido sustancialmente; la primera lo hizo casi al $9 \%$ por año entre 1968/1971 y $1977 / 1979$ y la segunda al $17.2 \%$ anual en el mismo período. El efecto combinado de ambas demandas permitió absorber una producción regional que creció a más del $14 \%$ por año.

Dentro de las frutas, la expansión de los cítricos y las manzanas $(7.5$ y $7.1 \%$ por año respectivamente) contrasta con el lento aumento del banano ( $1.9 \%$ anual) inferior al crecimiento de la población.

A comienzos de la década, dentro de la producción avícola, la de huevos era más importante que la carne. En 1970, la relación carne/huevos que era de 0.85 , pasó a 1.23 en 1980. La generalizada reducción del precio de la carne de aves respecto a la bovina se ha conseguido por disminución de los costos de producción, derivada principalmente de una mayor eficiencia y productividad. A ello debe sumarse la ingerencia activa de los grandes productores en el proceso de mercadeo, lo que contribuyó a reducir costos y a fomentar la demanda. De otro lado, la evolución del comercio mundial de la carne bovina, junto a la relativa inelasticidad de la oferta, contribuyeron a elevar los precios internos de esa carne. El proceso de urbanización por su parte también contribuyó al mayor consumo de carne de ave; las grandes ciudades están bien abastecidas por empresas avícolas muy dinámicas y eficientes.

El fuerte incremento de la producción avicola no estuvo acompañado por igual ritmo en la producción de cereales secundarios. La producción de maíz creció más lentamente $y$, al mismo tiempo, la parte producida para consumo humano disminuyó del 38 al $29 \%$, entre. gando progresivamente mayores volúmenes para la alimentación de aves y cerdos. La relativa estabilidad de los suministros y precios del maíz en los mercados internacionales - particularmente a partir de 1976- han repercutido sobre los niveles de los precios internos; si bien no llegaron a desalentar la producción tampoco la estimularon. A ello se sumó la competencia con el sorgo, cuya producción vióse de este modo alentada y cobró dinamismo. Si bien la producción regional de sorgo es aún reducida respecto a la de maíz, puede tratarse del inicio de una tendencia que se acentúe en los años ochenta.

La reducción del consumo de leguminosas parece una realidad en muchos países de la región. No está claro si la caída de su consumo ha determinado la reducción del ritmo de crecimiento de la producción o si ha ocurrido lo contrario. En el menor consumo de leguminiosas influyen su precio relativamente alto respecto a otros alimentos y el hecho de que exigen mayor gasto en combustible y tiempo de cocción; por su lado, el proceso de urbanización podría estar contribuyendo a la reducción del consumo por habitante. Las raíces y tubérculos son alimentos básicos principalmente en las areas rurales. El lento crecimiento de la producción de papa ( $1.7 \%$ por año) podría explicarse como consecuencia de una concentración de la demanda, resuitante de los cambios ocurridos en el peso relativo de la población urbana y rural. El encarecimiento del transporte y de la conservación de este tipo de productos también puede haber influido en la reducción de su consumo por habitante.

\section{Bases de este comportamiento}

El crecimiento de la producción continúa sustentándose principalmente en el aumento del área cosechada. Sin embargo, se ha manifestado ya una tendencia ascendente del aporte de la productividad al total producido. En la década de los años sesenta la expansión del área aportó dos tercios al aumento de lo cosechado, correspondiendo el tercio restante a la elevación de los rendimientos. Durante la década siguiente esa relación cambió significativamente. Tres quintas partes provienen ahora del área ampliada y dos quintas de las mejoras en los rendimientos. El área cosechada ha crecido al $1.7 \%$ por año, en tanto que los rendimientos lo hicieron al $1.4 \%$ anual (véase nuevamente el cuadro 2).

Se estima que se utiliza poco más de una cuarta parte de la superficie agricola cultivable. La mayor reserva de tierras $-72 \%$ de un total de alrededor de 600 millones ${ }^{17}$ está localiza-

17 CEPAL, 25 años en la agricultura de América Latina: Rasgos principales, $1950-1975$, Cuadernos de la CEPAL, N. 21, trabajo elaborado por la División Ayrícola Conjunta CEPAL/FAO, 1978. 
da en el trópico húmedo cuyo suelo se caracteriza por su baja fertilidad natural y su fragilidad. En el subtrópico se halla ubicado un $24 \%$ y el $4 \%$ restante en la subregion templada y en los sectores temperados de las cordilleras andinas. Algo más de la mitad $-54 \%$ de las reservas de tierras cultivables pertenecen a Brasil, Argentina, México y los países del Grupo Andino concentran gran parte del resto. En la década pasada, Brasil, Colombia, Argentina, Paraguay, Cuba, República Dominicana, Bolivia, Guatemala, Honduras y Costa Rica, aumentaron su área cosechada de modo más acelerado. La superficie cosechada regional ha pasado de 85 a 100 millones de hectáreas. De los 15 millones de aumento, el $62 \%$ corresponde a nuevos cultivos oleaginosos -principalmente soja-; $24 \%$ a cereales -trigo, arroz y sorgo-; $8 \%$ a caña de azúcar; $5 \%$ a café y el $1 \%$ restante se distribuye entre diversos cultivos, cuya área cosechada apenas aumentó.

La mayoría de las agriculturas nacionales elevaron sus rendimientos unitarios. $\mathrm{Y}$ a ello contribuyeron una combinación de factores, tales como la maduración de un trabajo orgánico de investigación y divulgación de resultados de los mismos, especialmente en lo que se refiere al mejoramiento genético de las plantas, a la aplicación de nuevas técnicas de fertilización y de control de pestes y a métodos avanzados de cultivo. En otros casos, influyeron exitosos programas de habilitación de tierras y la maduración de inversiones en regadío.

Tampoco puede dejar de mencionarse los avances derivados de una organización más eficiente - tanto técnica como económica-de las unidades productivas de tipo empresarial. Sin embargo, hay agriculturas que en el transcurso de los diez años examinados no lograron elevar en medida importante sus rendimientos; se advierten sí progresos efectivos en algunos cultivos, que no consiguen, sin embargo, influir sobre el nivel medio de productividad del conjunto de tierras cosechadas.

El acrecentamiento de la capacidad física de producción fue posible gracias al progreso técnico aplicado, diverso según las características de cada línea de producción, de sus exigencias en insumos técnicos y de la importancia de cada paquete tecnológico adoptado, medida por el número de sus componentes y por el gra- do de interdependencia entre ellos. Fue diferente, además, según los agentes económicos que introdujeron y aplicaron el cambio tecnológico y según las condiciones estimulantes o restrictivas de la producción que han prevalecido en los mercados.

En tres grupos de cultivos: cereales, sacarinos y oleaginosas se concentra el $77 \%$ de los fertilizantes utilizados. Esos cultivos ocupan a su vez el $72 \%$ del área cosechada, y representan el 70\% de los alimentos consumidos. El empleo de pesticidas está más generalizado que el de fertilizantes; sin embargo, hay gran predominio del algodón, seguido por cereales, frutas, café y papa, los que en conjunto absorben casi el $90 \%$ de los pesticidas empleados y ocupan el $63 \%$ del área cosechada (véase el cuadro 3 ).

En orden de importancia - determinada ésta por la magnitud de la aplicación media de fertilizantes por hectárea- se ubican la caña de azúcar, soja, cítricos, bananos, hortalizas, tabaco, algodón, papa, sorgo, arroz, trigo y maíz.

El consumo regional de fertilizantes ha pasado de 3.6 a 6.8 millones de toneladas de NPK, lo que implica un aumento del $8.5 \%$ anual (6.6\% los nitrogenados, $10.1 \%$ los fosfatados y 9.7\% los potásicos). En la década pasada se alteró la relación del consumo de fósforo y de potasio respecto al de nitrógeno. De $67 \%$ que fue la relación $\mathrm{P} / \mathrm{N}$ ha subido a $93 \%$, en tanto que el coeficiente $\mathrm{K} / \mathrm{N}$ subió de 45 a $60 \%$. El promedio regional está fuertemente influido por lo registrado en Brasil, donde el consumo de fertilizantes se cuadruplicó durante los años setenta $-16 \%$ anual - con crecimiento muy acelerado del consumo de fósforo y potasio debido a los requerimientos de ciertos cultivos y al contenido de nutrientes del suelo. Las producciones de clima cálido-húmedo, en especial de oleaginosas y caña de azúcar, explican el creciente uso de fertilizantes fosfatados y potásicos. Se desconoce en qué grado puedan haber contribuido en este sentido los cambios en las formulaciones y el posible uso más eficaz de fertilizantes en cultivos de clima templado.

Si se relaciona el consumo total de fertilizantes con el área cosechada anual se encuentra que la intensidad de fertilización ha pasado de 35 a 67 hectáreas. De otro lado, ha crecido la producción regional de fertilizantes, disminuyendo por lo tanto el aporte de las importacio- 
Cuadro 3

\section{AMERICA LATINA: CAMBIOS EN LA COMPOSICION DE LA PRODUCCION Y DE LA TIERRA COSECHADA Y COMPOSICION DEL CONSUMO DE FERTILIZANTES Y PESTICIDAS}

(En porcentajes)

\begin{tabular}{|c|c|c|c|c|c|c|}
\hline \multirow[t]{2}{*}{ Productos } & \multicolumn{2}{|c|}{$\begin{array}{l}\text { Composicion } \\
\text { de la } \\
\text { produccion }\end{array}$} & \multicolumn{2}{|c|}{$\begin{array}{l}\text { Composicion } \\
\text { del área } \\
\text { cosechada }\end{array}$} & \multicolumn{2}{|c|}{$\begin{array}{c}\text { Composición del consumo } \\
\text { de insumos técnicos } \\
1974-1976\end{array}$} \\
\hline & $\begin{array}{l}1969- \\
1971\end{array}$ & $\begin{array}{l}1978- \\
1980\end{array}$ & $\begin{array}{l}1969- \\
1971\end{array}$ & $\begin{array}{l}1978- \\
1980\end{array}$ & $\begin{array}{c}\text { Fertili- } \\
\text { zantes }\end{array}$ & $\begin{array}{l}\text { Pesti- } \\
\text { cidas }\end{array}$ \\
\hline \multicolumn{7}{|l|}{ I. CULTIVOS } \\
\hline Cereales & 17.8 & 16.4 & 55.7 & 50.0 & 25.2 & 18.8 \\
\hline Trigo & 3.3 & 3.1 & 10.1 & 9.8 & 6.7 & 2,1 \\
\hline Arroz & 4.0 & 4.0 & 7.6 & 7.7 & 6.8 & 2.5 \\
\hline Maíz & 8.6 & 7.2 & 30.7 & 225.6 & 5.9 & 9.7 \\
\hline Sorgo & 1.4 & 1.6 & 4.2 & 4.5 & 5.4 & 4.5 \\
\hline Ratces y tubérculos & 5.2 & 3.9 & 5.0 & 4.3 & 3.6 & 8.0 \\
\hline Papas & 2.1 & 1.8 & 1.2 & 1.1 & & \\
\hline Mandioca & 2.3 & 1.6 & 3.1 & 2.8 & & \\
\hline Sacarinos & 7.4 & 7.4 & 5.9 & 6.2 & 26.7 & 7.0 \\
\hline Caña de azúcar & 7.2 & 7.3 & 5.8 & 6.2 & 26.7 & 7.0 \\
\hline Leguminosas secas & 3.1 & 2.4 & 8.7 & 8.4 & 1.1 & 0.6 \\
\hline Frejol & 2.7 & 2.1 & 7.6 & 7.2 & 1.0 & \\
\hline Oleaginosas & 2.9 & 6.9 & 7.3 & 15.8 & 24.8 & 1.0 \\
\hline Soja & 0.8 & 4.5 & 1.9 & 10.6 & 21.8 & \\
\hline Hortalizas & 4.3 & 4.6 & 1.2 & 1.2 & 2.0 & 0.9 \\
\hline Frtetas & 9.1 & 9.3 & 2,2 & 1.9 & 7.9 & 13.9 \\
\hline Banano & 3.5 & 3.2 & 1.4 & 1.2 & 3.5 & 3.0 \\
\hline Cítricos & 1.7 & 2.4 & & $\ldots$ & 3.5 & 3.1 \\
\hline Bebidas y tabaes & 8.3 & 7.7 & 8.0 & 7.3 & 3.2 & 10.1 \\
\hline Cacao & 0.7 & 0.8 & 1.2 & 1.1 & 0.2 & \\
\hline Café & 6.5 & 5.7 & 6.2 & 5.6 & 1.4 & 9.6 \\
\hline Tabaco & 0.9 & 1.1 & 0.6 & 0.6 & & $\ldots$ \\
\hline Algodon en rama & 4.1 & 3.5 & 5,1 & 4.5 & 4.9 & 39.6 \\
\hline Total cultives & 62.7 & 61.7 & 100.0 & 100.0 & 100.0 & 100.0 \\
\hline \multicolumn{7}{|l|}{ II. PECUARIOS } \\
\hline Carnes & 23.1 & 23.7 & & & & \\
\hline Bovina & 14.7 & 13.3 & & & & \\
\hline Porcina & 3.8 & 4.0 & & & & \\
\hline Aves & 3.5 & 5.9 & & & & \\
\hline Otros & 14.2 & 14.6 & & & & \\
\hline Leche & 9.1 & 9.0 & & & & \\
\hline Huevos & 4.1 & 4.8 & & & & \\
\hline Total pecuarios & 37.3 & 38.3 & & & & \\
\hline Total produccion & 100.0 & 100.0 & & & & \\
\hline
\end{tabular}

Fuente: Elaborado por la División Agrícola Conjunta CEPAL/FAO a base de cifras de la FAO.

nes al consumo regional. La relación importación/consumo bajó de 58 a $51 \%$ en nitrógeno y de 56 a $38 \%$ en fósforo, en tanto que la de potasio se mantuvo en $99 \%$. Brasil, Colombia, Cuba y Uruguay son los países que más incrementaron su producción de abonos fosfatados.
El consumo de pesticidas pasó de 77 a 136 millones de toneladas de ingrediente activo, lo que implica una tasa del $8.4 \%$ de aumento por año. Los insecticidas representan el $49 \%$ del consumo de pesticidas, los fungicidas $24 \%$ y los herbicidas el $27 \%$ restante. Crecieron con ma- 
yor intensidad los herbicidas $-13.9 \%-$ y los

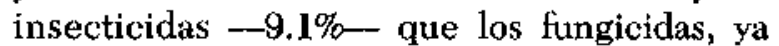
que éstos lo hicieron al $8 \%$ por año. Se aplican por hectárea de algodón - promedio regionalcuatro veces más pesticidas que en frutas, café, papa y caña de azúcar; a éstos siguen en importancia el tabaco, hortalizas, sorgo, mafz, arroz y trigo (véase nuevamente el cuadro 3 ).

En cuanto a maquinaria agrícola en servicio, el número de tractores ha pasado de 613 a $852 \mathrm{mil}$; aumento que implica un crecimiento del $4.8 \%$ por año. Los países que han elevado el número de tractores en más de un $70 \%$ son Brasil, Venezuela, Ecuador, Honduras y Boli- via; en $60 \%$ lo hicieron México y Panamá; y los demás países aumentaron su parque de tractores entre un 20 y $50 \%$. El número de hectáreas cosechadas por tractor - promedio regionalha bajado de 137 a 113 . La mecanización ha sido un componente importante del proceso de expansión del área cultivada.

El número de cosechadoras -trilladoras pasó de 95 a $117 \mathrm{mil}$, lo que implica un aumento de $3.1 \%$ anual. Venezuela, Guatemala, Ecuador y México elevaron el número de este tipo de máquinas en más de un 50\%; Argentina y Brasil lo habrian hecho en alrededor del $30 \%$.

\section{III}

\section{La agricultura y el sector externo}

No han variado sustancialmente las características de concentración, dependencia y vulnerabilidad de las exportaciones latinoamericanas. Se exporta una variedad limitada de productos que van a un número reducido de mercados importadores con definidas necesidades estacionales, particularmente de frutas y hortalizas. La conjunción de estas dos situaciones frena el dinamismo exportador regional y hace difícil reducir riesgos inherentes a las fluctuaciones de los volúmenes y precios de los productos exportados. La demanda externa que enfrenta América Latina no es estable, pues está determinada por los altibajos económicos de los principales países importadores. Esto ocurre particularmente con el café, el banano y el azúcar, productos de los cuales América Latina suministra buena parte de la oferta mundial. La inestabilidad de los ingresos originados por las exportaciones agrícolas continúa perjudicando el desarrollo agrícola y global latinoamericano.

\section{Exportaciones}

En los años setenta, los volúmenes agrícolas exportados por los países latinoamericanos aumentaron aproximadamente al $2.8 \%$ anual -entre 1950 y 1972 lo hicieron el $2.9 \%$ por año- mientras que la tasa mundial fue de casi $5 \%$ por año durante la década considerada. La participación de América Latina en las exportaciones agrícolas mundiales, que estuvo descendiendo en los decenios anteriores, se mantuvo relativamente constante-alrededor del $12 \%$ puesto que se redujo el ritmo de aumento de las exportaciones de Africa y se estancaron las ventas procedentes del Cercano Oriente. Hubo cambios en la composición y diversificación de las exportaciones latinoamericanas y se logró una mayor eficiencia en el proceso productivo que colocaron a la región en mejores condiciones para competir en los mercados internacionales.

El cuadro 4 recoge los cambios ocurridos en la parte exportada respecto al total producido por los países latinoamericanos, la que bajó del 18.4 al $17.1 \%$, entre 1970 y 1980 . Crecieron más rápidamente las exportaciones de,semillas oleaginosas, trigo, tabaco, té, frutas cítricas y manzanas. Los países latinoamericanos exportaron en el trienio 1978/1980 más del 50\% de su producción de té, café y cacao; menos del $50 \%$ de la fibra de algodón y soja; proporción que fue inferior al $40 \%$ en el caso del sorgo, azúcar, otras semillas oleaginosas, tabaco y manzanas, e inferior al $30 \%$ de lo producido el trigo y banano exportado. Ha sido importante el aumento de las exportaciones de leguminosas se- 
Cuadro 4

\section{AMERICA LATINA: CAMBIOS EN LA FRACCION EXPORTADA RESPECTO A LA PRODUCCION Y EN LA IMPORTADA RESPECTO AL CONSUMO APARENTE" (En porcentajes)}

\begin{tabular}{|c|c|c|c|c|}
\hline & \multicolumn{2}{|c|}{ Fracción exportada } & \multicolumn{2}{|c|}{ Fracción importada } \\
\hline & $\begin{array}{c}1969- \\
1971\end{array}$ & $\begin{array}{c}1978- \\
1980\end{array}$ & $\begin{array}{c}1969- \\
1971\end{array}$ & $\begin{array}{r}1978- \\
1980\end{array}$ \\
\hline Trigo & 18.1 & 27.6 & 39.2 & 47.6 \\
\hline Arroz & 3.7 & 5.6 & 3.9 & 4.7 \\
\hline Maíz & 18.1 & 15.2 & 3.3 & 10.7 \\
\hline Sorgo & 26.9 & 37.1 & 3.9 & 18.9 \\
\hline Raíces y tubérculos & 0.1 & 0.2 & 0.4 & 0.5 \\
\hline Azúcar & 40.4 & 35.9 & 1.7 & 3,2 \\
\hline Leguminosas secas & 2.4 & 8.7 & 4.3 & 7.0 \\
\hline Semillas oleaginosas y aceites vegetales & 23.5 & 38.8 & 17.6 & 22.1 \\
\hline Soja & 14.5 & 45.1 & 29,9 & 25.7 \\
\hline Hortalizas & 4.1 & 4.2 & 0.8 & 0.7 \\
\hline Frutas & 14.6 & 12.9 & 4.0 & 4.2 \\
\hline Banano y plátano & 23.5 & 22,1 & 1.7 & 1.4 \\
\hline Cítricos & 2.2 & 2.4 & 0.1 & 0,2 \\
\hline Manzanas & 28.2 & 31.6 & 20.5 & 18.7 \\
\hline Bebidas y tabaco & 70.8 & 57.0 & 16.5 & 9.4 \\
\hline Cacao & 73.6 & 53.0 & 24.4 & 4.3 \\
\hline Café & 77.1 & 61.6 & 8,3 & 4.9 \\
\hline Té & 67.7 & 79.8 & 59.3 & 62.5 \\
\hline Tabaco & 27.8 & 34.5 & 3.7 & 3.3 \\
\hline Algodón (fibra) & 60.1 & 45.0 & 11,0 & 7.7 \\
\hline Carne vacuna & 9.5 & 6.9 & 0.9 & 1.9 \\
\hline Carne ovina y caprina & 9.6 & 8.9 & 3.4 & 2.0 \\
\hline Carne porcina & 0.2 & 0.4 & 0.5 & 0.6 \\
\hline Carne de aves & 0.02 & 2.3 & 2.0 & 3.1 \\
\hline Huevos & 0.2 & 0.1 & 0.2 & 0.6 \\
\hline Lácteos & 0.4 & 1.1 & 8.6 & 10.7 \\
\hline Total & 18.4 & 17.1 & 9.7 & 12.8 \\
\hline Incremento anıal & $1977-1980$ & $1971=?$ & $1977-198$ & $71=8.0$ \\
\hline
\end{tabular}

Fuente:Elaboración de la División Agrícola Conjunta CEPAL/FAO, a base de cifras de la FAO.

aLas cantidades exportadas se valoraron y agregaron a precios del productor de 1969-1971. Las cantidades importadas se valoraron y agregaron a precios CIF.

cas, en buena parte debido a las ventas intrarregionales.

Los cambios anotados indican, de un lado, que ha disminuido la proporción que se venía exportando de cultivos tradicionales respecto al total producido, como en el caso del café, cacao, algodón, azúcar, maíz y carne vacuna, productos para los cuales el mercado doméstico viene tornándose cada vez más importante. Por otra parte, ha aumentado la fracción exportada de otros cultivos - trigo, oleaginosas, sorgo, manzanas, té, tabaco y carne de ave- lo que estaría indicando una mayor diversificación de las exportaciones, $y$, por lo tanto, una mayor articulación de las agriculturas nacionales con los mercados externos agrícolas. Esa mayor articulación forma parte importante de la creciente interdependencia entre naciones.

Nueve productos - café, azúcar, soja, harinas y tortas oleaginosas, algodón, cacao, banano, carne vacuna y ganado en pie, maiz y trigo en orden de importancia- contribuyeron con 
el $80 \%$ de las exportaciones agrícolas a comienzos de los años ochenta. A pesar de la lograda diversificación de las exportaciones, el $58 \%$ de los ingresos de los países por exportaciones agricolas provinieron de tres productos: caté, azúcar y oleaginosas, incluyendo los subproductos de estas últimas.

Las exportaciones siguen destinándose fundamentalmente a países desarrollados; alrededor del $75 \%$ va a Estados Unidos, la CEE y otros países industrializados, $15 \%$ a los países en desarrollo y a los de economía centralmente planificada y el $10 \%$ restante constituye el comercio intrarregional.

\section{Importaciones}

Los volúmenes agrícolas importados por los paises latinoamericanos aumentaron al $8 \%$ anual en los años setenta - lo hicieron al 5.3\% anual entre 1965 y $1976-y$ al $10 \%$ por año entre 1975 y 1980 . La aceleración del rítmo de aumento se debió a las mayores compras de trigo, maíz, sorgo, aceites vegetales, productos lácteos, frejol y azúcar.

El cuadro 4 muestra los cambios registrados en la década pasada con la fracción importada respecto al consumo aparente. El trigo es con mucho el producto importado más significativo, le siguen las semillas oleaginosas, los cereales para alimentación animal — maíz y sorgo-, los productos lácteos, las carnes, café, azúcar, leguminosas, frutas y cacao.

Las importaciones agricolas alcanzan al $12 \%$ del abastecimiento regional. Una tercera parte de los productos agrícolas que importan los países latinoamerianos proviene de la misma región y algo más del $60 \%$ procede de países desarrollados, dependencia que se agrava por el hecho de que esos suministros son manejados por un reducido número de grandes empresas exportadoras que concentran la oferta, en particular, la de cereales.

El grado en que los distintos países dependen de las importaciones para completar su abastecimiento interno presenta notoria varie- dad. Argentina, Brasil, Colombia, Guatemala, Nicaragua, Paraguay y Uruguay importan menos del $5 \%$ de su oferta interna; Ecuador, El Salvador, Haiti, Bolivia, Costa Rica, Honduras, México y Panamá se aproximan al promedio regional de $10 \%$; para Cuba, Chile y Jamaica la cifra oscila entre 20 y $30 \%$, se eleva a casi el $50 \%$ para Trinidad y Tabago y Barbados y trepa a casi el $75 \%$ para Granada.

\section{Balance del comercio agrícola}

El valor en dólares corrientes de las exportaciones agricolas de los países latinoamericanos habría pasado de 6.8 a 23.1 miles de millones entre 1969/1971 y $1977 / 1979$. Durante el mismo período el valor de las importaciones habría aumentado desde 1.7 a 6.7 miles de millones de dólares. El saldo en favor de la región habría pasado de 5.1 a 16.4 miles de millones de dólares corrientes.

A los países de ALADI corresponden dos tercios del saldo favorable; para los países andinos su saldo comercial agrícola continúa siendo positivo, aun cuando en magnitudes decrecientes. Los países del MCCA tienen un balance positivo y creciente, en cambio los países del CARICOM enfrentan déficit sucesivos en su balance comercial agrícola externo.

El cuadro 4 es ilustrativo respecto a la evolución y la magnitud de los principales productos excedentes exportables y de los productos deficitarios que originan las importaciones más cuantiosas. Permite apreciar, además, corrientes paralelas en varios de ellos que salen $y$ llegan a la región en virtud de las exportaciones e importaciones de los países y que constituyen un punto de convergencia importante para un mayor comercio intrarregional.

Vale la pena insistir en el aumento paulatino de la tendencia deficitaria observable en los productos calificados como 'críticos' -trigo, oleaginosas, cereales secundarios, lácteos y carnes- en los que la región puede aumentar su autoabastecimiento mediante un drástico reordenamiento de su producción y comercio. 


\section{IV}

\section{El desarrollo de las fuerzas productivas}

Han ocurrido cambios importantes respecto a las fuerzas productivas agrícolas en el transcurso de los años setenta. Algunos fueron más evidentes, otros quedaron oscurecidos por las características propias del sector agrícola y, finalmente otros han pasado inadvertidos, confundidos dentro del comportamiento productivo sectorial. La percepción -a veces incompleta- de esos cambios permite, de un lado, apreciar cómo se fue acentuando la diferenciación productiva y social entre los agentes económicos comprometidos directamente en el proceso productivo.

Como es sabido, las fuerzas productivas agrícolas -en otras palabras, la estructura agraria- latinoamericanas son heterogéneas, lo que constituye una característica fundamental y decisiva en el funcionamiento de la agricultura regional. Las variadas y profundas diferenciaciones dentro del sector condicionan su marcha y confieren pluralidad a los procesos económicos, sociales y políticos que ocurren en la agricultura.

Para simplificar el análisis se concentra la atención en los dos segmentos más importantes: empresariado y campesinado. Los procesos de reforma agraria y otras acciones redistributivas de tierras y aguas han influido en el evidente proceso de desconcentración de la propiedad de la tierra y la consecuente ampliación del segmento intermedio, lo que se refleja en el acrecentado número de unidades económicas de tamaño pequeño a mediano. Este grupo intermedio está acrecentando su importancia y funcionalidad dentro de los agricultores.

El segmento empresarial agrupa a aquellas formas de hacer agricultura que comúnmente se identifican como agricultura comercial moderna, plantaciones, haciendas; en otras palabras, a aquellas formas capitalistas que tienen distintos grados de avance en materia de organización y tecnificación de sus instrumentos operativos.

El segmento campesinado agrupa también realidades productivas muy diversas, tales como agricultores pequeños acomodados, pe- queño productor de naturaleza familiar, agricultores campesinos pobres de áreas agrícolas seculares, colonos en áreas de expansión de la frontera agrícola, medieros y otros. Tienen todos ellos como rasgos comunes el trabajo familiar y el tamaño limitado de sus unidades económicas.

\section{El segmento empresarial}

El empresario agrícolà latinoamericano es una realidad marcada por claras diferenciaciones a lo largo de la historia de cada país. Sin constituir un fenómeno nuevo es distinto al de lustros atrás. A los cambios propios del paso del tiempo se agregan nuevas características -especialmente en el caso de los más avanzados-que tienen que ver con su mayor homogeneidad como segmento productor; el tamaño económico de mediano a grande de sus empresas y el grado de control de los recursos productivos; las magnitudes de su capital y la composición de sus inversiones; la complejidad y aún la 'sofisticacion' de los sistemas tecnológicos que adopta; el grado de especialización respecto a las líneas de producción a que se dedica; el perfeccionamiento introducido en materia de organización técnica y administrativa de su actividad productiva; las modalidades laborales a que se acogen para evitar conflictos sociales; la profusión de interrelaciones con sectores no agrícolas, en particular financieros, industriales, comerciales y con medios de comunicación; y, finalmente, el fortalecimiento de los vínculos que los une a grupos próximos a los centros de poder y decisión, con miras a mantener presencia vigilante en las esferas oficiales responsables del desarrollo agrícola y rural.

Son selectivos en materia de localización de sus tierras, tanto respecto a fertilidad natural y topografía favorable, como a cercanía a los mercados. Los patrones tecnológicos adoptados los han conducido a una reestructuración social interna de sus unidades productivas; requieren cuadros restringidos de trabajadores especializados, que se complementen con ma- 
no de obra no calificada, preferentemente temporal.

Han logrado que el Estado contraiga con ellos compromisos cuando adopta diversas medidas de política, entre otras, cambiarias, de comercio exterior, de crédito, de regulación de mercados, de costo del dinero, de salarios y normas de contratación de mano de obra, las que han favorecido su fortalecimiento.

Una forma indirecta de apreciar el desarrollo del segmento empresarial moderno consiste en examinar la intensidad de la formación de capital en la agricultura y el grado de acentuación $\rightarrow 0$ cambio si hubiera tenido lugar- del patrón de mecanización que antes habían adoptado.

Como un intento de aproximación al análisis de las dimensiones y composición de las inversiones que viene realizando el sector empresarial, se ha configurado - según los censos agrícolas nacionales e información adicional disponible para algunos países - una situación ilustrativa, promedio regional, del gasto de las fincas medianas y grandes con producción mixta (cultivos y ganadería).

E1 cuadro 5 muestra las modificaciones en la composición del gasto total que se habrían registrado durante las dos últimas décadas e ilustra sobre las tendencias resultantes de dichos cambios, En primer lugar, la parte del gasto destinada a inversiones habría crecido más rápidamente que la dedicada a gastos de operación; habrían pasado de una quinta a una cuarta parte del gasto total. El aumento resultante es coincidente con los indicadores cualitativos que apuntan hacia una acelerada formación

Cuadro 5

\section{AMERICA LATINA: CAMBIOS EN LA COMPOSICION DEL GASTO EN FINCAS MEDIANAS Y GRANDES CON PRODUCCION DE CULTIVOS Y GANADERIA, 1960-1980}

(En porcentajes)

\begin{tabular}{|c|c|c|c|c|c|}
\hline & \multicolumn{3}{|c|}{ Composición del gasto } & \multicolumn{2}{|c|}{$\begin{array}{c}\text { Tasas de incremento } \\
\text { del gasto }\end{array}$} \\
\hline & 1960 & 1970 & 1980 & $\begin{array}{l}1960- \\
1970\end{array}$ & $\begin{array}{l}1970 \\
1980\end{array}$ \\
\hline \multicolumn{6}{|l|}{$\begin{array}{l}\text { I. Gastos de capital } \\
\text { Edificaciones, regadio, }\end{array}$} \\
\hline habilitación de suelos & 5.4 & 6.3 & 6.7 & 4.6 & 5.0 \\
\hline Plantaciones, huertas y viñedos & 2,6 & 2.9 & 3.0 & 4.2 & 5.2 \\
\hline Maquinaria, equipos, herramientas & & & & & \\
\hline medios de transporte & 6.2 & 8.2 & 11,4 & 6.5 & 7.9 \\
\hline Ganado de cría y animales de tiro & 6.8 & 5.6 & 4.9 & 2.3 & 2.9 \\
\hline $\begin{array}{l}\text { Subtotal } \\
\text { II. Gastos de operación }\end{array}$ & 21.0 & 23.0 & 26.0 & 4.5 & 5.7 \\
\hline 11. Remuneración de la mano de obra & 31.6 & 24.6 & 18.1 & 1.0 & 1.2 \\
\hline Semillas, fertilizantes, pesticidas & 19.4 & 21.6 & 23.0 & 4.7 & 5.1 \\
\hline $\begin{array}{l}\text { Combustibles, lubricantes y } \\
\text { arriendo de maquinaria }\end{array}$ & 5.1 & 7.1 & 9.5 & 7.0 & 7.5 \\
\hline $\begin{array}{l}\text { Arriendo de tierras, agua y } \\
\text { animales de trabajo }\end{array}$ & 3.3 & 3.9 & 3.8 & 5.3 & 4.2 \\
\hline $\begin{array}{l}\text { Alimento del ganado, vacunas y } \\
\text { medicamentos }\end{array}$ & 12.8 & 13.1 & 13.0 & 3.8 & 4.4 \\
\hline Intereses y otros gastos financieros & 3.8 & 3.8 & 3.5 & 3.6 & 3.8 \\
\hline Otros gastos & 3.0 & 3.2 & 3.1 & 3.2 & 4.2 \\
\hline Subtotal & 79.0 & 77,0 & 74.0 & 3.2 & 4.0 \\
\hline Total & 100.0 & 100.0 & 100.0 & 3.5 & 4.4 \\
\hline
\end{tabular}

Fuente: Elaborado a base de censos agrícolas nacionales e información adicional para algunos países. 
de capital en fincas medianas y grandes. A su vez dentro de los gastos de operación, los correspondientes a semillas, fertilizantes, pesticidas y combustibles habrian crecido más rápidamente que el resto, lo que a su vez es coherente con la mayor adquisición y uso de maquinaria, equipos, herramientas y medios de transporte. En otras palabras, el gasto en formación de capital y en operación ha estado fuertemente influido por y asociado a la adopción de innovaciones mecánicas, químicas y biológicas.

En los años sesenta la compra de maquinaria y equipos, la construcción de edificios y la habilitación de tierras habrian representado un $55 \%$ de la formación de capital, porcentaje que habría subido al $63 \%$ a comienzos de los años setenta y al $70 \%$ a principios de los años ochenta. Por lo tanto, el cambio más notorio y evidente ha consistido en el aumento de la maquinización, entendiéndose por tal la incorporación de maquinaria, equipos e instalaciones y medios de transporte, crecimiento que ha exigido la construcción de edificios apropiados y ha facilitado la realización de nuevas y más complejas mejoras territoriales y obras de regadío. En la década de los años sesenta se percibe un renovado énfasis en las inversiones para tecnificar el proceso productivo agrícola, como reacción ante tres grupos de medidas de política: i) de abaratamiento del capital a través de créditos con interés muchas veces subsidiado, rebajas preferenciales de aranceles aplicables a las importaciones de maquinaria e insumos agroquimicos, o su venta por parte del Estado a precios subsidiados; ii) la construcción, ampliación y diversificación de la infraestructura extrapredial; y iii) los programas de asistencia técnica para la producción, la comercialización intema, la exportación, el fomento de determinados cultivos considerados prioritarios para la expansión de la agroindustria y la ampliación de la frontera agrícola.

Bajo estas circunstancias, el proceso de formración de capital en la agricultura ha sido impulsado por la ampliación de los mercados y las tacilidades de acceso a ellos; por los niveles de los precios de los productos y factores de producción; por la infraestructura física disponible o Ia certeza de su ampliación en plazos determinados; por la disponibilidad de innovaciones técnicas y el grado de difusión de sus resul- tados en lo agronómico y económico; por la disponibilidad de créditos en condiciones favorables; por precios abaratados de bienes de capital e insumos para el proceso de producción agrícola; por los progresos en la articulación de la agricultura con la industria y con el comercio de productos agrícolas; y por la disponibilidad de ideas y estudios sobre proyectos agricolas y su posterior adecuación a los criterios gubernamentales para el fomento selectivo de líneas de producción. Y por el contrario, situaciones poco claras o desfavorables en torno a estos elementos impulsores han acentuado las restricciones en que la agricultura desenvuelve sus actividades productivas.

Los empresarios agricolas que forman este segmento productor invierten en función de la rentabilidad que esperan obtener. Muestran, por lo tanto, una conducta económica sensible y selectiva ante medidas e instrumentos de políticas adoptados precisamente para evitar el deterioro de la rentabilidad agrícola. El dinamismo de estos empresarios -reflejado en lo productivo y técnico- es evidente, sobre todo en las áreas agrícolas más desarrolladas y en los rubros de producción más rentables. Poseen conocimientos y recursos propios que les permiten aprovechar el ambiente propicio para realizar inversiones en la agricultura generadas por el Estado, y hacer uso racional y rápido de tecnologías bioquímicas y mecánicas probadas y listas para ser utilizadas.

Al comienzo de los años sesenta, los gastos de operación asociados al proceso de tecnificacion, tales como semillas mejoradas, fertilizantes, pesticidas, alimentos concentrados para el ganado, vacunas y medicamentos, combustibles, lubricantes y arriendo de maquinaria, habrian representado el $31 \%$ del total, porcentaje que habría subido a 37 en 1970 y a 44 en 1980. Al pronunciarse el patrón de tecnificación del proceso productivo éste se vio acompañado por una reducción del gasto destinado a remunerar la mano de obra, el que habría bajado del 32 al $18 \%$, a lo largo de los veinte años considerados. Cabe destacar que en la década de los años setenta la remuneración a la mano de obra creció más rápidamente que durante la década anterior, pero dada la notoria diferencia con la velocidad de crecimiento alcanzada por 
los demás tipos de gasto de operación, su participación dísminuyó acentuadamente.

Las inversiones en agricultura realizadas por el Estado tuvieron el propósito de inducir, orientar y facilitar la inversión privada, $y$ han influido, decidida y activamente, en el comportamiento y composición de la producción, pero no han generado por sí mismas aumentos de las cosechas. Estimaciones del Instituto Internacional de Investigación de Políticas Alimentarias IFPRI ${ }^{18}$ indican que aproximadamente un $10 \%$ del crecimiento de la producción agrícola latinoamericana registrado entre 1950 y 1978 , se debe al efecto de los estímulos de diversa índole generados por la inversión pública agxícola. La inversión pública se ha concentrado, coincidente y sostenidamente, en obras de regadío, habilitación de suelos, mejoramiento de las instalaciones de almacenamiento y de mercadeo agrícola, y en la adquisicón de máquinas y equipos requeridos por los servicios de investigación y asistencia técnica. Estuvo incorporada a los programas estatales de fomento de la producción, así como a los de reforma agraria y colonización, ${ }^{19}$ capacitación, investigación, extensión y formación de cooperativas.

El nivel y composición de las inversiones, y en general del gasto privado en la agricultura estuvo influido por la intensidad de la inflación que soportaron las economías nacionales. Cuando las tasas de interés son negativas o sensiblemente inferiores a las vigentes en el mercado, la inflación suele estimular compras abultadas de maquinaria y equipos y la construcción de edificios que en otras circunstancias no se habrían apresurado. Se ha sostenido que los costos actuales de la inversión deben ser ventajosos frente a los futuros, seguramente más elevados, lo que ha originado inversiones especulativas. Aumentó así la demanda por tractores y equipos agrícolas, $y$, en consecuencia, se acrecentó la capacidad de la fuerza de trabajo mecánica, lo que a su vez ha conducido tanto a la expansión de la tierra culti-

${ }^{18}$ IFPRI, “Government Expenditures in Agriculture in Latin America", Research Report N." 23, Victor Elias, mayo de 1981 .

${ }^{19}$ La inversión pública en la agricultura ha sido de alrededor del $5 \%$ de las inversiones públicas tótales; este porcentaje es coincidente con los análisis realizados por la División Agrícola Conjunta CEPAL/FAO y por el IFPRI. vada dentro del total de tierras de la empresa agrícola, como a la adquisición, por diversos medios, de más tierras que absorban esa capacidad mecánica sobredimensionada, a costa, unas veces, de la disponibilidad de tierras de la agricultura campesina, y en otras, de la incorporación de nuevas tierras al proceso productivo.

El mayor uso de encarecidos insumos técnicos y equipos agrícolas ha conducido a su vez a mayores necesidades de crédito. Se ha comprobado que el monto absoluto del crédito agrícola se ha incrementado sustancialmente..$^{20}$ En algunos países ha llegado a ser cinco veces mayor de lo que fue a comienzos de los años sesenta; en otros, aunque el crecimiento no ha sido tan espectacular, por lo menos se ha duplicado. Si se examina el coeficiente que indica la relación entre el monto del crédito agrícola y el producto regional generado por el sector agrícola se encuentra que aquél estuvo elevándose sostenidamente; así, pasó de alrededor del $35 \%$ en 1965 al $40 \%$ en 1970 , y sobrepasa el $60 \%$ a comienzos de los años ochenta.

De otra parte, la información disponible indica que en ciertos países ha crecido la relación entre el crédito agrícola y el crédito total; en otros esa relación se habría mantenido estable y en otros habria disminuido. Como promedio regional, se estima que dicha relación fue del orden del $13 \%$ en 1965 , la que habría subido al $16 \%$ en 1970 y en años recientes se aproxima al $20 \%$. Esto significa que a través deJ crédito institucional ha venido concretándose una moderada mayor asignación de recursos para la agricultura.

La acentuación del encarecido patrón de tecnifìcación y las mayores necesidades de crédito han determinado un incremento de la relación deuda/ingresos de las empresas agrícolas medianas y en particular de las grandes. E1 servicio de esa deuda está incidiendo sobre la situación financiera de las empresas y puede haber llevado al deterioro de la relación costo/beneficio de modo que podría haberse reducido el ingreso neto de los agricultores en tér-

20 J. C. Abbot, "Agricultural Credit Institutions in Asia and Latin America", en Boletín mensual de economia y estadistica agrícolas, FAO, Romat, Vol. 22, N. ${ }^{\circ} 12,1974$. 
minos reales y en nominales en ciertos casos. Forzados por esas circunstancias buscaron afanosamente el refinanciamiento de su deuda y aumentaron sus necesidades de efectivo para cubrir movimientos de caja, lo que podría deprimir las inversiones futuras. Todo ello ha generado acentuadas presiones por aumentos sustantivos del volumen del crédito agrícola, lo que ha ocurrido, junto a una mayor demanda por préstamos financiados por recursos de muy variado origen, en particular no agrícola y procedentes del exterior, ampliándose y ramificándose así los mercados fínancieros agrícolas.

Esto último viene repercutiendo, de un lado, en el ínicio de una tendencia a la formación creciente de sociedades anónimas propietarias de las empresas agrícolas, lo que como contrapartida implica una disminución progresiva de la propiedad agrícola individual. Por otra parte en la agricultura se ha expandido y diversificado el mosaico de intereses de grupos no agrícolas; intereses urbanos, industriales, comerciales y financieros se pronuncian, reclaman y presionan por cambios en determinadas medidas e instrumentos de política, confrontando y/o tamizando la influencia de los grupos netamente agrícolas en las decisiones más importantes de la política agrícola nacional.

\section{El campesinado}

La agricultura campesina, como fuerza productiva agricola, tiene una significación e importancia indiscutidas. Diversas investigaciones, algunas completadas sobre casos específicos y otras aún en marcha, explican la dinámica de su funcionamiento $y$ demuestran su articulación dentro del modelo de acumulación del sistema económico global. ${ }^{\text {I1 }}$

La agricultura campesina se caracteriza porque la motivación fundamental de su actividad económica consiste en asegurar un nivel de ingreso familiar que permita reproducir su fuerza de trabajo y reponer sus herramientas y aperos de labranza. El trabajo familiar constituye la base sobre la que se asienta la organiza-

\footnotetext{
21FAO, "La agricultura hacia el año 2000: Problemas y
} opciones de América Latina", Roma, febrero de 1981. ción de las labores productivas, con las que se busca la reproducción, simple o ampliada, de la unidad familiar. ${ }^{22}$

La trayectoria del campesinado a lo largo de la década pasada ha puesto en evidencia su capacidad de cambio ante la repercusión, aislada o combinada, de fenómenos y procesos de diversa naturaleza e intensidad. Entre éstos cabe destacar la dinámica poblacional y los movimientos migratorios; la mayor interacción de lo urbano con to nural cuya trascendencia ha modificado las aspiraciones y la actividad económica del campesinado como así sus relaciones sociales; los progresos logrados en torno a la integración física y el desarrollo de la infraestructura correspondiente que facilitaron el intercambio, los desplazamientos y permitieron que la agricultura campesina se abra a espacios más amplios y tenga una nueva perspectiva respecto a sus propias posibilidades y dificultades; la ampliación y organización de los mercados, lo que afectó líneas tradicionales de producción, estimuló otras nuevas y alteró, a veces drásticamente, las vinculaciones productivas-comerciales del campesino; y por último, las intervenciones gubernamentales orientadas a modificar las estructuras agrarias mediante procesos de reforma agraria, así como el accionar de los servicios estatales de apoyo a la agricultura, que de uno $u$ otro modo generaron cambios en la agricultura campesina.

Mención aparte merece lo relativo al cambio tecnológico. No obstante las dificultades derivadas de las características de los paquetes tecnológicos que los mercados ofrecen o fueron impulsados por las políticas oficiales, y que no son los más apropiados a las condiciones y necesidades de la agricultura campesina, algunos de los componentes de esos paquetes fueron utilizados en forma selectiva por el campesinado. Emplea uno o varios insumos tecnológicos, estableciendo a base de su propia experiencia, paquetes tecnológicos simples y adaptados a sus condiciones económicas y ecológicas. Hay demasiadas evidencias de que ello es así, lo que desmiente la supuesta indife-

222Véanse los trabajos sobre el campesinado presentados en este mismo numero de la hevista de la CEPAL, en especial los de E. Ortega, R. Brignol y J. Crispi, y K. Heynig. 
rencia del campesinado a la adopción de nuevas tecnologias; lo que ocurre es que éstas se han desarrollado en forma limitada en comparación con la oferta disponible para el sector empresarial.

Con el propósito de aproximarse al conocimiento de las dimensiones de la agricultura campesina, se ha elaborado el cuadro 6. Más allá de las debilidades estadísticas que contengan las cifras básicas que fundamentan dicho cuadro, los resultados obtenidos son coincidentes con apreciaciones cualitativas contenidas en numerosos estudios e informaciones nacionales.

A base de los censos agropecuarios nacionales se ha estimado que en Latinoamérica, y a comienzos de los años ochenta, a los pequeños agricultores correspondería casi cuatro quintas partes de las unidades económicas agrícolas y dispondrían aproximadamente de un quinto de la tierra comprendida en todas esas uni- dadés económicas; relación que en términos de tierra bajo cultivo sería algo más de un tercio y representaría más de dos quintos del área total cosechada. Su contribución productiva al consumo interno es significativa; alcanzaría a dos quintos del total producido con ese destino y a un tercio de la producción para exportación. Su producción es fundamental para el abastecimiento de productos de consumo popular como sucede con el frejol, papa y maíz. No deja de ser importante su aporte a la producción del café y arroz y contribuiría con más de dos tercios de la producción de carne porcina.

La pequeña producción familiar, prove niente de unidades de dimensiones económicas reducidas, con frecuencia permanece opacada por el evidente progreso productivo de la agricultura empresarial, llegando inclusive a desconocerse, muchas veces, su participación en el funcionamiento y dinámica del sector como tal. Sin embargo, lo relativo a la creciente

Cuadro 6

AMERICA LATINA: ESTIMACION PROVISIONAL SOBRE DIMENSIONES DE LA AGRICULTURA EMPRESARIAL Y LA DEL PEQUEÑO PRODUETOR A COMIENZOS DE LOS AÑOS SETENTA

(En porcentajes)

\begin{tabular}{lcc}
\hline Indicadores & $\begin{array}{c}\text { Agricultura } \\
\text { empresarial }\end{array}$ & $\begin{array}{c}\text { Pequeno } \\
\text { productor }\end{array}$ \\
\hline Número de unidades económicas & 22 & 78 \\
Area total comprendida en las unidades & 82 & 18 \\
Area arable comprendida en las unidades & 63 & 37 \\
Area utilizada en las unidades & 56 & 41 \\
Producción para consumo interno & 59 & 32 \\
Producción para exportación & 68 & 41 \\
Producción de cultivos permanentes & 59 & 53 \\
Producción de cultivos de ciclo corto & 47 & 51 \\
Producción de maíz & 49 & 77 \\
Producción de trejol & 23 & 61 \\
Producción de papa & 39 & 32 \\
Producción de arroz & 68 & 41 \\
Producción de café & 59 & 21 \\
Producción de caña de azúcar & 79 & 24 \\
Existencias de ganado bovino & 76 & 78 \\
Existencias de ganado porcino & 22 & \\
\hline
\end{tabular}

Fuente: Elaborado a base de los censos agropecuarios nacionales.

'La columna 'pequeño productor' comprende unidades de tipo fumiliar. Para la diferenciación de las unidades empresariales se introdujeron criterios de tamaño. Los porcentajes reflejan, en alguna medida, lo que ocurre con la agricultura campesina, pero no muestran Ias dimensiones y contribuciones de lo que se entiende estrictamente por tal.

hComprende área utilizada con cultivos; no incluye pastos. 
monetarización del pequeño productor está suficientemente documentada en casi todos los países de la región, así como sus vinculaciones ramificadas con los mercados agrícolas. De otro lado, también hay evidencias de que la diferenciación productiva entre los sectores empresarial y campesinado, está contribuyendo a que en el seno mismo de la agricultura se acentúe la desigualdad en la distribución del ingreso. Esto último, a su vez, guarda relación con lo que está ocurriendo en el sistema económico global.

Según la CEPAL, cálculos recientes sobre siete países -Argentina, Brasil, Colombia, Chile, México, Pení y Venezuela-que abarcan en conjunto casi $80 \%$ de la población y poco más del $90 \%$ del producto de América Latina, indican que en 1975 el $10 \%$ más rico de los hogares recibía algo más del $47 \%$ del ingreso total, mientras que, en el otro extremo, el $40 \%$ más pobre ni siquiera alcanzaba a captar el $8 \%$ de este. El fuerte grado de desigualdad resulta más evidente si se contrastan los ingresos medios de ambos grupos; durante ese mismo año el del tramo rico equivalía a más de 24 veces el del tramo pobre."

Dichos cálculos indican que la desigualdad entre 1960 y 1975 , lejos de atenuarse se agravó, al caer levemente el ingreso percibido por el $40 \%$ más pobre, y aumentar, también levemente, la participación en el mismo del $10 \%$ más rico y la del $20 \%$ de los hogares situado inmediatamente por debajo de éste.

Según la FAO, en 1973 unos 85 millones de personas $-70 \%$ de la población agrícola latinoamericana- vivían en condiciones de subsistencia. De ese total, unos 45 millones eran asalariados agrícolas y unos 40 millones pequeños propietarios. Percibieron alrededor del $35 \%$ del ingreso agrícola total, con un ingreso per cápita estimado de 115 dólares de 1970. Los agricultores medianos representaban el $28 \%$ de la población agrícola y obtuvieron el $43 \%$ de los ingresos agrícolas. Los grandes propietarios $-2 \%$ de la población agrícola - captaron el $22 \%$ del ingreso, con una cifra media per cápita de 2560 dólares de 1970; en sus

\footnotetext{
23CEPAL., "El desarrollo de América Latina en los anos ochenta" (E/CEPAL/G,1150), febrere de 1981.
}

manos estaba el $47 \%$ de las tierras bajo cultivo, mientras que los campesinos sólo poseían el $2.5 \%$ de ellas. ${ }^{24}$

El Comité Especial sobre Reforma Agraria de la FAO, en su informe de 1971 -diez años después de la Reunión de Punta del Estellegó a la conclusión de que en América Latina la expropiación de tierras había alcanzado apenas al $15 \%$ de las potencialmente expropiables, y que sólo se había incorporado a los programas y acciones de reforma agraria un $22 \%$ de los posibles beneficiarios. Esta situación parecería haberse prolongado hacia fínes de los años setenta. Algunos países impulsaron acciones de reforma agraria que modificaron, y en algunos casos sustancialmente -como en Perú- el régimen anterior de tenencia de la tierra. No se ha efectuado una posterior evaluación de los resultados de los programas y acciones de reforma agraria emprendidos en América Latina; los contradictorios argumentos y juicios de valor emitidos y contenidos en distintas publicaciones reavivan las viejas interrogantes sobre el particular.

El crecimiento de la producción agrícola no logró aliviar la pobreza. Muy poco se ha avanzado en la solución del problema de cientos de miles de campesinos minifundiarios y de asalariados sin tierras. Hay indicios de que el número absoluto de personas que subsiste en el campo en condiciones de vida precarias y hasta miserables siguió aumentando a medida que creció la población agrícola, pese a la intensa migración a las ciudades y a las mayores dimensiones de la economía agrícola regional. La división espontánea de la tierra, debida a muchas causas, ha aumentado notablemente el número de explotaciones agrícolas de tamaño reducido $\mathrm{y}$ a veces inusitadamente pequeño, por lo que cabe prever un agravamiento de la situación en el futuro.

El estilo de desarrollo general y el agrícola en particular, no han permitido una más adecuada distribución de las oportunidades de empleo y de ingresos. Los viejos problemas de

\footnotetext{
${ }^{24} \mathrm{FAO}$, "Examen y análisis de la reforma agraria y el desar rollo rural en los países en desarrollo, desde mediados de los años sesenta", Conferencia Mundial sobre Reforma Agraria y Desartollo Rural (CMRADR/INF.3), Roma, julio de 1979 .
} 
tenencia de la tierra y los nuevos resultados de la concentración no sólo de tierras sino fundamentalmente de capitales, producción e ingresos que caracterizan el proceso de modernizacion agrícola, podrian estar agravando las condiciones de la población rural en materia de ocupación e ingreso, o por lo menos, no se advierten cambios positivos.

Existen dudas acerca de los efectos de la expansión empresarial agrícola sobre el empleo y la naturaleza del mismo. Se ha discutido por mucho tiempo si el número total de jornadas aumenta o disminuye con la adopción de patrones tecnológicos modernos. Aunque no se cuenta con una evaluación adecuada al respecto, lo que sí parece claro es que la naturaleza del empleo ha tendido a cambiar con la adopción de tecnologías que hacen uso intensivo de capital; cambio que se tradujo en una disminución del número de trabajadores contratados en forma permanente e incremento de la contratación temporal de mano de obra, la que viene desde los minifundios o desde los pueblos vecinos, e incluso migrante desde las ciudades, para ciertas labores no fácilmente mecanizables.

Según PREALC, ${ }^{25}$ en 1980 alrededor del $35 \%$ de la fuerza de trabajo agrícola regional estaría ocupada por la agricultura empresarial -que comprende tanto a los empresarios modernos como a los apegados a formas tradicionales de hacer agricultura-y el $65 \%$ restante refugiada en la agricultura campesina. En Bolivia, la agricultura empresarial emplearia menos del $10 \%$ de la fuerza de trabajo, porcentaje que oscilaria entre 20 y $30 \%$ en Brasil, Ecuador, Panamá, Perú y Venezuela; superaría el $40 \%$ en Guatemala, se ubicaría entre 40 y $50 \%$ en Colombia, El Salvador y México, para exceder el $50 \%$ en Argentina, Costa Rica, Chile y Uruguay. De acuerdo a esa misma fuente, la fuerza de trabajo agrícola estaría reduciéndose en términos absolutos en Argentina y Uruguay, prácticamente no crecería en Chile y Venezuela, aumentaría menos que el promedio regional

${ }_{25}$ Programa Regional del Empleo para América Latina $y$ el Caribe, PREALC, "El subempleo en América Latina: Evolución histórica y requerimientos futuros", Santiago, abril de 1981.
$-0.9 \%$ por año- en Bolivia, México y Perú, y continuaría aumentando sustancialmente en Guatemala y El Salvador.

La mengua de la participación de la fuerza de trabajo agrícola regional respecto a la total -bajó del 42.1 al $35.6 \%$ entre 1970 y $1980-$ está indicando un desplazamiento continuo de una parte de los problemas sociales inherentes a la pobreza rural hacia las grandes ciudades. Según la CEPAL, ${ }^{26}$ en 1950 el sector industrial -incluyendo en él a la manufactura, construcción, electricidad y transporte- ocupaba un $22 \%$ de la población económicamente activa y un $27 \%$ del mismo en 1980 . La fuerza de trabajo en la industria creció al $2.7 \%$ entre 1950 y 1970 $y$ al $3.8 \%$ entre 1970 y 1980 . Si se adicionan sus importantes efectos indirectos sobre las restantes actividades económicas, la industrialización que en 1950 influía sobre más del $35 \%$ de la fuerza de trabajo, en 1980 aumentó su participación al $47 \%$. En otras palabras, cerca de la mitad de la ocupación regional está vinculada al proceso de industrialización de las economias nacionales.

\section{La labor del Estado}

El desarrollo de las fuerzas productivas agrícolas estuvo influido por la ampliación de los mercados -de productos, factores y tecnológicos- a los que ellas se vinculan, por el grado de apertura al exterior de las economías nacionales -en lo económico, técnico y financiero-, por el sentido e intensidad de los flujos de recursos transferidos intersectorialmente y por la acción del Estado. Si se concentra la atención en esta última, $y$ sin participar en la discusión relacionada con el grado de eficiencia del Estado como ordenador del desarrollo agricola, puede afirmarse que éste tuvo una participación relevante en la expansión de la productividad agrícola. En los últimos decenios, su responsabilidad y participación en los ámbitos económico y social de la agricultura fue creciente, en la generalidad de los países de la región.

En algunos paises se ha cuestionado la efi-

26CEPAL, "El desarrollo de América Latina en los años ochenta" (E/CEPAL/G.I150) febrero de 1981. 
cacia de las prestaciones asistenciales directas realizadas por el Estado, $y$ como alternativa se ha transferido dichas tareas al sector privado, el cual ha recibido los estímulos financieros requeridos para el cumplimiento de tales actividades. De otra parte, se ha criticado enérgicamente la intervención estatal en los mercados agricolas. Entre otras consideraciones, se ha puesto de relieve la arbitrariedad de tales intervenciones, sus altos costos y las distorsiones resultantes. Se propicia, por el contrario, la casi total prescindencia del Estado, dejando a las fuerzas del mercado el ajuste y superación de los desequilibrios entre oferta y demanda y la atenuación de las fluctuaciones de los precios. Se espera que tales ajustes conduzcan a una mayor eficiencia productiva y eleven el grado de competividad entre productores.

Las esferas en que el Estado ha venido participando y que han repercutido sobre el desarrollo de las fuerzas productivas tienen que ver con la tendencia a concebir el desarrollo de la agricultura dentro de un marco más orgánico, acudiendo para ello a la formulación de estrategias y planés de desarrollo agrícolas, y son escasos los países que no los hayan formulado. A pesar de las limitaciones que puedan haber tenido dichos planes y lo limitado de los logros conseguidos en la práctica, su formulación ha posibilitado, por lo menos un mayor conocimiento de los recursos y de sus potencialidades, la identificación de las posibilidades $y$ restricciones de las tecnologías disponibles, el estudio del comportamiento de los mercados domésticos y externos, análisis éstos que han aportado elementos de juicio y facilitado la percepción de los conflictos y dificultades como así de las perspectivas de la agricultura.

Los países latinoamericanos, en general, han fortalecido su capacidad de formulación y de ejecución de proyectos agrícolas, como consecuencia tanto de la puesta en marcha de procesos de planificación agrícola como por reacción ante las exigencias y normas establecidas por los organismos internacionales de financiamiento. Las agencias estatales han progresado en lo relativo a preparación de proyectos, tanto para el desarrollo de la infraestructura básica que sustenta e impulsa la producción sectorial, como de desarrollo de líneas específicas de producción.
Los gobiemos han realizado esfuerzos más o menos exitosos en el plano institucional, acudiendo para ello a distintas formas jurídicas que les han permitido establecer organismos, cuyos propósitos básicos han sido dar agilidad y mejorar la eficiencia de la acción estatal en el ámbito rural. Infortunadamente tales propositos se han visto, con frecuencia, obstaculizados por hipertrofia burocrática y excesiva concentración operativa; por eso y para escapar a tales restricciones, numerosos países han creado instituciones autónomas o corporaciones regionales de desarrollo, con funciones y resultados diversos.

Los organismos responsables de la investigación agrícola y del financiamiento del desarrollo sectorial, parecen ser los que más progresos han logrado en lo que se vincula tanto con la calidad de sus cuadros técnicos, como con la simplificación de procedimientos operativos. No obstante, siguen cuestionados por el alcance de sus funciones y resultados, los que suelen estar sesgados en beneficio del segmento empresarial. Hay carencia notable de tecnologías apropiadas a las necesidades y posibilidades de la agricultura campesina, que incorporen los conocimientos y experiencias que el campesino tiene de sus sistemas de cultivo y que a su vez incluyan las relaciones con los ecosistemas que integran.

Una cuarta esfera donde la acción estatal ha alcanzado mayor significación que antes es la del financiamiento de la actividad agrícola. Las formulaciones presupuestarias han conducido a un cierto ordenamiento del gasto público, en función de los objetivos sectoriales, aun cuando se mantienen rigideces entre gasto corriente y de capital. Los requerimientos para sostener al aparato público en expansión entran en conflicto con las necesidades de financiamiento de las inversiones, previstas en las acciones de apoyo efectivo a los productores.

Múltiples circunstancias han propiciado y obligado al Estado a participar de modo cada vez más complejo en beneficio de la actividad agrícola nacional. Han tenido que ver tanto con reacciones frente a situaciones económicas internacionales específicas, como con la búsqueda de medios de influencia acelerada y múltipìe sobre el desarrollo económico y social de este sector vital, aunque atrasado. El aumento y 
la diversificación de la actividad estatal en torno a la agricultura - excepto en los países que aplican políticas deliberadas para reducirlasha correspondido más bien más a una actitud pragmática encaminada a resolver a través del tiempo problemas especificos, antes que a una orientación concreta derivada de la planificación agrícola. Bajo esas condiciones no ha sido fácil anticipar y dar continuidad a la política agrícola, ni insertarla apropiadamente en las estrategias nacionales de desarrollo.

Las medidas e instrumentos de política y las acciones gubernamentales en la agricultura estuvieron orientadas - con orden de prioridad y énfasis diverso- según el estilo de desarrollo de cada país a: i) influir en el volumen producido, atendiendo situaciones cambiantes de los mercados internos y externos y las variaciones de los precios de los productos agrícolas y de los insumos requeridos para producirlos; ii) mejorar el abastecimiento de alimentos, los sistemas de mercadeo y la distribución de alimentos entre los grupos mas pobres y vulnerables; iii) modificar las funciones de producción $\mathrm{y}$ estimular el cambio tecnologico; iv) fomentar o restringir selectivamente las exportaciones e importaciones agricolas; $v$ ) intentar una más rápida incorporación de la agricultura campesina a la vida nacional, tanto en lo social como en lo económico y político; vi) facilitar la integración física de los espacios geográficos menos articulados a la economía nacional; vii) conservar los recursos naturales $y$ preservar el medio ambiente; $y$ viii) producir combustibles líquidos que sustituyan parcialmente el consumo de los derivados del petróleo.

Esas decisiones de política se han traducido en los recursos asignados: el volumen del gasto público efectivo y las dimensiones del crédito institucional. Distinta ha sido la prioridad que a través del tiempo se concedió a cada una de estas áreas de intervención y/o participación gubernamental. Sin embargo, cuando han aparecido indicios de que la producción agrícola nacional podría ser insuficiente para contribuir al abastecimiento de alimentos en el grado en que tradicionalmente lo estuvieron haciendo, se han volcado recursos y se han intensificado los esfuerzos del aparato público para que se acrecienten las cosechas a expensas, por lo general, no de asignaciones a otros sectores económicos sino de las destinadas a acciones de contenido social en el ámbito agrícola. Difícil es aislar y apreciar cuantitativamente la repercusión que en lo productivo y en lo social tuvo cada decisión de política o cada acción gubernamental de apoyo y prestación de servicios a la agricultura. De todos modos es evidente que en alguna medida contribuyeron a los aumentos del volumen producido; los cambios de prioridades y énfasis influyeron decididamente en las modificaciones observadas en la formación de capital a nivel de finca, en la adopción de cambios tecnológicos y en el uso acrecentado de insumos agroquímicos y en la acelerada adquisición de maquinarias y equipos.

\section{V \\ El estado nutricional y la producción de alimentos}

Las producciones nacionales de alimentos continúan siendo, en general, el componente principal del abastecimiento de alimentos. Las agriculturas nacionales se han articulado e integrado progresivamente a los mercados domésticos y, por lo tanto, en ellas han repercutido las características de estos últimos. Una consiste en que la expansión de la demanda es relativamente regular -al contrario de lo que puede ocurrir en los mercados intemacionales- y, por lo tanto, las fluctuaciones de los precios son menos intensas, y cuando se presentan tienden a ser suavizadas como resultado de intervenciones gubernamentales, lo que influye sobre la producción y contribuye a que ésta se organice y ordene. Por ello, la evolución de las líneas de producción cuyo destino principal es el mercado doméstico, se ha ajustado al comporta- 
miento de la demanda interna, influida, a su vez, por el aumento de los ingresos medios y por los avances del proceso de urbanización.

Entre 1970 y 1980 , la producción regional de alimentos por habitante creció al $0.9 \%$ por año, en tanto que la agrícola total por habitante lo hizo al $0.8 \%$ anual. El consumo aparente de alimentos por habitante, valorado en términos monetarios, ha crecido al $1.1 \%$ por año, ritmo superior al de la producción y que fue posible debido a la contribución que al abastecimiento hicieron las importaciones.

El consumo aparente total de alimentos de la región, valorado en términos monetarios, habría crecido al $3.6 \%$ anual en el mismo período. El consumo de cultivos habría aumentado al $3.5 \%$ por año, en tanto que el de pecuarios a casi el $4.0 \%$ anual. Si se considera al consumo aparente en términos de energia alimentaria, habría aumentado sólo al $3.2 \%$ por año. El distinto ritmo de aumento del consumo aparente, medido por su valor monetario y calorico, se debe al diferente aporte que en uno y otro caso hacen los productos pecuarios, que son de alto valor monetario y reducido contenido calórico, pero de todos modos aportantes de proteínas de alto valor nutritivo.

\section{Estado nutritivo, adecuación calórica y régimen alimenticio}

Dentro del problema nutritivo de Latinoamérica cabe diferenciar las enfermedades por déficit y las por excesos de alimentos. Entre las por déficit a su vez se distinguen las derivadas de carencias específicas -anemias nutricionales, bocio endémico e hipovitaminosis $\mathrm{A}-\mathrm{y}$ la desnutrición calórico-proteica, resultante de la subalimentación y mal aprovechamiento de los alimentos.

La desnutrición calórico-proteica afecta principalmente a menores de cinco años; se estima que alrededor del $15 \%$ de los niños de la región sufren de desnutrición media a alta. La situación por pafses y subregiones es diferente; los problemas más graves se presentan en los países de América Central y el Caribe, seguidos por los países andinos. De todas maneras en los años sesenta se ha percibido un leve mejoramiento general del estado de nutrición de la niñez latinoamericana.
El mejoramiento de los ingresos medios y las crecientes disponibilidades medias de alimentos no fueron suficientes para neutralizar otros factores condicionantes de la desnutrición, tales como hábitos alimentarios defectuosos, deficientes condiciones de salud y sanidad, además de ausencia de educación alimentaria-nutricional. La pobreza rural y urbana está acompañada por la desnutrición más acentuada; para superarla es necesario actuar sobre las causas y raíces mismas de la pobreza.

La relación entre la disponibilidad de energía alimentaria y las recomendaciones de consumo calórico y que se conoce como el grado de adecuación, permite apreciar las variaciones que a través del tiempo han ocurrido, respecto al estado alimentario de la población. ${ }^{27}$ La adecuación calórica promedio regional reciente es de $107 \%$.

Como es lógico, los niveles de adecuación son bastante diferentes entre países. Es bien conocido que en el interior mismo de cada país se pueden diferenciar varios tramos de población con distinta adecuación calórica. Siete países conforman un primer estrato con adecuación superior a $110 \%$-Argentina, Costa Rica, Cuba, Jamaica, México, Paraguay y Uruguay-y entre los cuales destacan Argentina $y$ Paraguay con los niveles más altos: 127 y 120 respectivamente. El segundo tramo, entre 100 y $110 \%$, está formado por seis países - Brasil, Chile, Guyana, Nicaragua, Panamá, Venezuela-y aquí resaltan Chile, Nicaragua y Brasil por sús niveles más elevados. El tercer estrato, menos de $100 \%$, comprende al resto de países: presentan los niveles más bajos Bolivia y Haití, con 89 y $90 \%$, respectivamente. En general, casi todos los países han elevado su adecuación calórica durante los años setenta, y lo hicieron con mayor intensidad aquellos que se encontraban en una situación inicial más desfavorable.

El cuadro 7 muestra el aumento en la disponibilidad de energía alimentaria por habitante latinoamericano, por grupos de productos

\footnotetext{
27El promedio recomendado para Aunérica Latina es de 2400 calorias diarias por habitante; las recomendaciones de consumo para Argentina y Uruguay se aproximan a las 2660 calorías; para algumos países de Ámérica Central y del Caribe baja a 2250 .
} 
y algunos productos en particular. Llama la atención el elevado incremento de la disponibilidad de carne de ave, seguida a distancia por la de aceites, azúcar, huevos, leche, hortalizas y frutas. Ha crecido ligeramente la disponibilidad de arroz y carne vacuna. De otra parte, el consumo de trigo no aumentó y ha disminuido el de maíz, papa, mandioca leguminosas, carne ovina y caprina.

Los diversos ritmos de aumento en la disponibilidad de energía alimentaria han generado cambios en el régimen alimentario medio regional. El incremento del aporte calórico proveniente del azúcar está ligado al creciente consumo de bebidas y alimentos elaborados y de al to costo por unidad de energia alimentaria.

Cuadro 7

AMERICA LATINA: CRECIMIENTO DE LA DISPONIBILIDAD DE ENERGIA ALIMENTARIA, POR PRODUCTOS 1970-1974 A 1978-1980

(En porcentajes)

\begin{tabular}{|c|c|c|c|}
\hline \multirow{6}{*}{$\begin{array}{l}1 . \\
2 . \\
3 . \\
4 . \\
5 .\end{array}$} & \multirow[b]{2}{*}{ Trigo } & \multirow{2}{*}{$\begin{array}{c}\begin{array}{c}\text { Tasa de } \\
\text { erecimiento } \\
\text { anual total }\end{array} \\
\\
2.5\end{array}$} & \multirow{2}{*}{$\begin{array}{c}\begin{array}{c}\text { Tasa de } \\
\text { crecimiento } \\
\text { anual por } \\
\text { habitante }\end{array} \\
0.0\end{array}$} \\
\hline & & & \\
\hline & Arroz & 3.4 & 0.8 \\
\hline & Maíz & $-1,3$ & -3.6 \\
\hline & \multirow{2}{*}{$\begin{array}{l}\text { Azúcar centrifugada } \\
\text { en bruto }\end{array}$} & -0.2 & -2.7 \\
\hline & & 5 & 29 \\
\hline 6. & Leguminosas & $\begin{array}{l}5.5 \\
0.6\end{array}$ & $\begin{array}{r}2.9 \\
-1.9\end{array}$ \\
\hline 7. & Aceites & 7.1 & 4.4 \\
\hline 8. & Hortalizas y frutas & 3.7 & 1.2 \\
\hline & Came vacuna & 3.2 & 0.7 \\
\hline \multirow[t]{2}{*}{10.} & Came porcina & 35 & 1.0 \\
\hline & ovina y caprina & 2.7 & -5.1 \\
\hline 11. & Carne de aves & 12.2 & 9.5 \\
\hline & Huevos & 5.0 & 2.4 \\
\hline \multirow[t]{2}{*}{13.} & Leche & 4,0 & 1,4 \\
\hline & Otros ${ }^{\mathrm{a}}$ & 2.9 & 0.4 \\
\hline \multicolumn{2}{|c|}{ Total calórico } & 3.1 & 0.6 \\
\hline
\end{tabular}

Fuente: Elaboración de la División Agricola Conjunta CEPAL/FAO a partir de información de FAO y CELADE (población).

"No incluye pescado.
El crecimiento del consumo de aceites, came de aves, huevios y leche implica, en términos generales, un mejoramiento del régimen alimenticio medio regional. Ahora bien, la distinta caída de la contribución calórica de cereales y leguminosas puede ser preocupante en la medida en que esto afecte a los sectores de menores ingresos. La combinación adecuada de cereales y leguminosas - dos tercios los primeros y un tercio los segundos- aporta una ingesta equilibrada de aminoácidos esenciales de valor nutritivo similar al de las proteínas de origen animal que son de mayor costo.

El cuadro 8 permite apreciar las modificaciones acaecidas en el régimen alimenticio medio. Aumentaron las calorías vacías o pobres en proteínas, disminuyeron las provenientes de vegetales equilibrados, se mantiene el aporte de sales, minerales y vitaminas y también aumentaron ligeramente las calorías de origen pecuario. Esos cambios ocultan situaciones nutricionales más graves en los grupos pobres, quienes seguramente incrementaron el consumo de calorías vacías y redujeron más acentuadamente el de leguminosas.

\section{La inflación y los precios de los alimentos}

Uno de los más graves problemas de alcance internacional en los últimos años es la inflación; y en América Latina ha sido mayor la intensidad del fenómeno inflacionario que en los países industrializados. Mientras en los países miembros de la OCDE los precios al consumidor subieron en promedio al $8.2 \%$ anual entre 1969 y 1979 , el incremento promedio en América Latina fue de $37.5 \%$. Esos ritmos inflacionarios presentan diferencias por quinquenios. Durante el primero, los países de la OCDE tuvieron una inflación media anual de un $7.4 \%$ y América Latina en su conjunto del 24.3\%; en el período $1975-1979$, los países de la OCDE, en cambio, incrementaron ligeramente su inflación, la que alcanzó al 9\% anual, en tanto que América Latina soportó un aumento considerable, ya que llegó al $51.9 \%$ por año. Durante el último decenio, ni un solo pais latinoamericano tuvo una tasa promedio anual inferior al $5 \%$, mientras que entre 1965 y 1970 , fueron 15 paises los que presentaron ese merior ritmo inflacionario. 
Cuadro 8

VARIACIONES EN LA COMPOSICION DEL APORTE CALORICO DEL CONSUMO APARENTE DE LA REGION, POR HABITANTE

$\begin{array}{ll}1971- & 1978- \\ 1974 & 1980\end{array}$

I. De origen vegetal

1. Calorias vactas o pobres en proteinas

Azúcar

Aceites

Raíces $y$ tubérculos

$\begin{array}{rr}33 & 37 \\ 17 & 20 \\ 8 & 11 \\ 8 & 6 \\ & \\ 43 & 38 \\ 14 & 13 \\ 10 & 10 \\ 14 & 11 \\ 5 & 4\end{array}$

3. Aportadores de sales minerales y vitaminas Frutas y hortalizas

Total de origen vegetal

II. De origen animal

1. Carne de vacuno

2. Carne ovina

3. Carne porcina

4. Carne de aves

5. Huevos

6. Leche

Total de origen animal

Otrosu

Total
Interesa examinar, en especial, la relación entre inflación y niveles de precios de los alimentos, tanto por la influencia que estos últimos pueden haber tenido en la generación, intensificación o moderación de las presiones inflacionarias, como por los efectos del proceso inflacionario sobre la alimentación de la población y, en particular, de los sectores de menores ingresos. Es bien sabido que éstos gastan precisamente una mayor proporción de su ingreso en alimentos.

El cuadro 9 muestra la relación entre el índice de aumento del precio nominal de los alimentos, respecto al incremento del costo de vida. Entre 1970 y 1975 el precio de los alimentos creció más rápidamente que el costo de vida en 15 de los 16 países examinados y con intlación más intensa; entre 1975 y 1979 en más de la mitad de dichos países el precio de los alimentos creció más velozmente y, en los otros, el alza en el costo de vida apenas superó el alza de los precios de los alimentos. De otro lado, el alza de los precios reales de los alimentos - respecto a su nivel en 1970 - fue más intensa en el primer quinquenio, con excepción de Argentina. Entre 1975 y 1979 , los precios reales de los alimentos bajaron en ocho países; en los demás países, los precios fueron ligeramente más elevados que en 1975. En 1979, en 18 a 21 países analizados, los precios reales de los alimentos tenían niveles superiores a los registrados en 1970.

Puede decirse que, en general, los precios de los alimentos aumentan más rápidamente que la intlación cuando el proceso inflacionario se intensifica y que, por el contrario, cuando dicho proceso se atenúa los precios de los alimentos crecen con ritmos menos acelerados que la inflación. En cuanto a los precios reales de los alimentos, puede afirmarse que se elevan en períodos de mayor inflación. Los precios reales de los alimentos de prácticamente todos los paises son superiores en 1980 respecto a sus niveles de 1970.
"No incluye pescrado.

\section{Fuente: Elaborado por la División Agrícola Conjuntu CEPAL/FAO a base de datos de FAO para produc- ción y cousumo y CELADE para población.} (n) 
Cuadro 9

AMERICA LATINA: INFLACION Y PRECIOS DE LOS ALIMENTOS, 1970 - 1979

\begin{tabular}{lccrr}
\hline & $\begin{array}{c}\text { Indice del precio de los } \\
\text { alimentos respecto al } \\
\text { indice del costo de vidat }\end{array}$ & $\begin{array}{c}\text { Indice de precios reales } \\
\text { de los alimentos } \\
1970=100\end{array}$ \\
\cline { 2 - 5 } Países & $\begin{array}{c}1970- \\
1975\end{array}$ & $\begin{array}{r}1975- \\
1979\end{array}$ & 1975 & 1979 \\
\hline Argentina & 1.00 & 1.01 & 99.7 & 103.1 \\
Barbados & 1.15 & 0.93 & 111.9 & 97.8 \\
Bolivia & 1.14 & 0.92 & 112.2 & 97.1 \\
Brasil & 1.11 & 1.01 & 109.8 & 101.1 \\
Chile & 1.07 & 0.95 & 126.8 & 91.9 \\
Colombia & 1.20 & 1.00 & 117.5 & 100.3 \\
Costa Rica & 1.02 & 1.19 & 101.3 & 104.2 \\
Ecuador & 1.29 & 0.99 & 118.4 & 99.6 \\
Haití & 1.10 & 0.95 & 106.3 & 98.9 \\
Jamaica & 1.13 & 1.03 & 108.6 & 102.3 \\
México & 1.13 & 0.95 & 107.4 & 96.4 \\
Paraguay & 1.20 & 1.10 & 110.7 & 104.7 \\
Perú & 1.17 & 1.04 & 110.2 & 105.8 \\
República Dominicana & 1.21 & 0.53 & 110.3 & 86.4 \\
Trinidad y Tabago & 1.23 & 0.79 & 114.0 & 10.7 \\
Uruguay & 1.02 & 1.02 & 104.2 & 103.1 \\
\hline
\end{tabular}

Fuente: CEPAL, Anuario Estadfstico 1979, elaborado por la División Agricola Conjunta CEPAL/FAO.

\section{VI}

\section{Agricultứa y energía}

\section{La agricultura como usuaria de energia}

El empleo de energía por parte de la agricultura puede examinarse a través del aporte que hacen el esfuerzo humano, la energía desplegada por los animales de tiro, la motriz generada por la maquinaria agrícola, la energía incorporada a los insumos modernos (en particular fertilizantes y pesticidas) y la utilizada en el proceso de transporte, transformación y distribución de alimentos. Si el análisis se concentra únicamente en la energía comercial utilizada en el proceso productivo agrícola, se llega al resultado provisional de que la agricultura latinoamericana consume casi el $2 \%$ del consumo total de energía comercial de la región y alre- dedor de un $3 \%$ del consumo regional de combustibles fósiles líquidos. ${ }^{28}$

Los fertilizantes, a lo largo de su proceso de fabricación, envasado, transporte y distribución, absorben alrededor del $49 \%$ de la energía comercial aplicada a la agricultura latinoamericana, los pesticidas un $3 \%$ y la maquinaria agrícola explica el $48 \%$ restante. Se ha estimado que en los países desarrollados el sistema aljmentario absorbe alrededor de un quinto de la energía comercial total, siendo gran parte de la misma consumida en el proceso de transforma-

${ }^{28} \mathrm{CEPAL}$ " $\mathrm{El}$ desarrollo agrícola en los años ochenta", E/CEPAL/G.1159, febrero de 1981. 
ción y distribución de los alimentos elaborados. Dentro de esas actividades destacan el enlatado, la deshidratación artificial, el enfriado, congelado y reconstitución de concentrados altamente procesados. ${ }^{2 \theta}$

La energía incorporada al consumo regional de fertilizantes ha crecido al $12 \%$ anual entre $1969 / 1970$ y $1979 / 1980$, de manera que ha pasado de 2.4 a 7.4 millones de toneladas equivalentes en petróleo. Si el análisis se centra únicamente en los fertilizantes producidos en América Latina, esa participación es bastante inferior ya que la producción regional -que tiende a crecer - representa actualmente el $42 \%$ del empleo regional de fertilizantes. Dentro del total de fertilizantes, los nitrogenados, debido tanto a los requerimientos de su proceso de fabricación y distribución cuanto a la magnitud de su empleo como abono, son con mucho los que mayor energía absorben: $82 \%$; le siguen los fosfatados con $13 \%$ y los potásicos con el $5 \%$ restante.

En los años setenta, el parque de maquinaria y equipo agrícola regional hizo un consumo creciente de combustibles fósiles líquidos. Entre 1971 y 1976 dicho consumo creció al $5.2 \%$ anual, ritmo que se habría elevado al $6.7 \%$. anual entre 1076-1980 $-6 \%$ por año promedio para la década - tasa similar a la de aumento del consumo total regional de petróleo y sus derivados. El consumo habria subido de 2.1 a 3.5 millones de toneladas equivalentes en petróleo.

La información disponible indica que no. más del $10 \%$ de las unidades económicas agrícolas de la región - que comprenden alrededor del $28 \%$ del área bajo cultivo- hacen uso exclusivo de fuerza motriz mecánica, que un $34 \%$ -que representa aproximadamente el $52 \%$ del área bajo cultivo-emplea en forma combinada fuerza motriz mecánica y tracción animal, y que e] $56 \%$ restante -alrededor del $20 \%$ de la superficie bajo cultivo- utiliza exclusivamente fuerza de trabajo humana y tracción animal. Se explica así que la agricultura regional participe,

${ }^{29}$ Banco Mundial, Energy and agricutture: An overview, Alfredo Sefir-Younis, agosto de 1981. Documento preparado para el Seminario "Cambio técnico en el agro latimoamerícano: Situación y perspectivas en la década de $1980^{\prime \prime}$, Organizado por IICA/PNUD, $10^{\circ}$ al 3 de septiembre de 1981, San José, Costa Rica. como ya se indicó, con sólo alrededor del $3 \%$ en el consumo regional total de combustibles fósiles liquidos. Los indicadores sobre tipos de maquinaria empleada en las labores de cultivos y sobre las características del proceso de expansión del área bajo cultivo, dan sustento a la aseveración de que en el proceso productivo agrícola regional todavía predominan la tracción animal y el esfuerzo humano.

Los cultivos realizados en forma mecanizada y con aplicación plena de los progresos bioquímicos - en varios países y casos- más que han duplicado los rendimientos físicos por hectárea, pero esa elevación de la productividad ha exigido que se multiplique varias veces el consumo de energía comercial: combustibles, fertilizantes y pesticidas.

En 1980, el precio internacional del petróleo era 12 veces mayor que en 1970. Con escasas excepciones la trayectoria de los precios internos en los países latinoamericanos guard $\delta$ estrecha relación con lo ocurrido en el ámbito mundial. Los precios internacionales de los fertilizantes aumentaron bastante menos que los del petróleo, pero aun así los de los nitrogenados se han triplicado y Ios de los fosfatados duplicado. Políticas nacionales encaminadas a abaratar los insumos tecnológícos para la agricultura han permitido que los agricultores paguen por los fertilizantes precios menores que los intermacionales.

El alza de los precios del petróleo y sus. derivados constituye el componente principal de la elevación de los costos de producción del sector empresarial y, por lo tanto, influyó en el alza consiguiente de los precios de los alimentos.

Hasta fines de 1973 la tendencia de la relación precios agrícolas/precios de los combustibles fósiles líquidos, era favorable a los primeros. De ahí en adelante, en los países latinoamericanos - con pocas excepciones y distinta intensidad- se deterioró la capacidad de compra de los agricultores, expresada en términos de petróleo. En efecto, entre 1970 y mediados de 1973, el poder adquisitivo agrícola, medido por la relación precios agrícolas/precios del petróleo subió de 1.11 a 1.37 ; luego, entre fines de 1973 y 1977 , esa misma relación bajo de 1.02 a 0.68 . Y lo ocurrido con los precios del petróleo entre 1977 y 1980 acentuó dicha pérdida. 


\section{La agricultura como fuente de energía}

El aumento sostenido de los precios de los combustibles fósiles líquidos y sus repercusiones sobre el balance de pagos permitió considerar a la agricultura como fuente alternativa de combustibles líquidos. Está avanzada la investigación orientada a identificar materias primas que puedan generarlos y están definidos los procesos de conversión correspondientes. La caña de azúcar, la yuca o mandioca y el sorgo sacarífero - calificados como cultivos energéticos- concitan la mayor atención. Para varios países, y a corto plazo, el etanol -alcohol etílico- procedente de la destilación del mosto de la caña de azúcar y del almidón de la yuca, aparecen como fuente suplementaria de combustibles líquidos. Los aceites vegetales son combustibles aptos para los motores diesel, pero por razones técnicas y económicas se piensa en ellos como opciones a mediano plazo; el metanol -aicohol metílico- proveniente de la celulosa también aparece como una solución a mediano plazo y en función de la evolución de los precios del petróleo.

La caña de azúcar es, por ahora, el cultivo energético más importante. La mandioca o yuca ha concitado la atención dadas las considerables ventajas que podría tener por tratarse de un cultivo poco exigente en materia de suelos y clima, lo que no sucede con la caña de azúcar. Por su parte el cultivo de la mandioca genera más empleo que la caña, lo que contribuye a una mayor distribución de ingresos. Ahora bien, si la caña de azúcar se cultiva en pequeñas explotaciones vinculadas a minidestilerías -20 mil litros de alcohol-m en vez de hacerlo en grandes plantaciones ligadas a grandes destilerías, indudablemente sus desventajas se reducen con relación a la mandioca.

En varios países se llevan a cabo investigaciones y se experimenta con almidón de mandioca. Los problemas encontrados - y prácticamente solucionados- se vinculan al empleo de semillas apropiadas para el cultivo destinado a la producción de alcohol, con los pasos que deben darse para convertir un cultivo tradicionalmente familiar en otro tipo comercial, con lotes sembrados de $100 \mathrm{y}$ más hectáreas. Al respecto, han surgido interrogantes referidas a la preparación del suelo, distancia entre las plantas, control fitosanitario, prácticas adecuadas de cosecha y mecanización de la misma. A más de estos problemas, solucionables con el tiempo, se añaden los relativos a las destilerías, dado que la destilación del alcohol del almidón de mandioca constituye un proceso más lento y complicado que el de la caña de azúcar. El almidón debe transformarse primero en azúcar, para luego ser fermentado y destilado.

El Problema Nacional del Alcohol (PROALCOOL) de Brasil, iniciado a fines de 1975, constituye el mayor esfuerzo latinoamericano -y seguramente mundial- de cultivos energéticos. La producción brasileña de alcohol ha registrado un gran crecimiento durante los últimos años, pasando de 664 millones a 3400 millones de litros entre 1976/1977 y 1979/1980, y podria llegar a 4200 millones de litros en 1981. En total por ahora suman 384 los proyectos aprobados para la instalación de destilerías, los que representan una capacidad de destilación equivalente a 8000 millones de litros por año, a la que debe añadirse la previa al programa -900 millones de litros-y que en su conjunto alcanza al $84 \%$ de la meta de $10700 \mathrm{mi}$ llones de litros/año, postulada para 1985.

La mezcla de alcohol anhidro y bencina implantáda en todo el país, posibilitó en 1980 la sustitución de un $17 \%$ del consumo de gasolina. En 1980 PROALCOOL introdujo la distribución de alcohol hidratado a escala comercial, como combustible exclusivo de unos 350 mil vehículos producidos al efecto o con motores modificados.

Otros países de la región también han iniciado esfuerzos para producir combustibles líquidos a partir de cultivos energéticos. El aprovechamiento de desechos vegetales como biogás - gas metano - también está adquiriendo interés; se realizan investigaciones sobre distintos tipos de digestores para ampliàr la producción de dicho gas. A su vez la leña y el carbón vegetal han cobrado renovada importancia en la búsqueda de energía comercial basada en la biomasa.

Utilizar la agricultura para producir cultivos alimentarios y energéticos plantea interrogantes respecto a la futura composición de la producción agrícola, a variaciones de los precios relativos y al grado de modificación técnica 
a que pueden ser sometidas las agriculturas nacionales. De otro lado, la expansión productiva agrícola está fuertemente condicionada por la disponibilidad y precios de los combustibles fósiles líquidos. Se trata, pues, de opciones complejas y difíciles cuyos méritos relativos pueden ser muy distintos en los diversos paises de la región.

\section{VII}

\section{La industrialización de la agricultura}

En la mayoría de los países latinoamericanos se está regístrando un acentuado proceso de industrialización de la agricultura. En la medida en que se han establecido y/o consolidado los eslabones ${ }^{30}$ de la cadena agroindustrial, se fueron comprometiendo $-\mathrm{y}$ a veces transformando- las bases productivas del sector agrícola. La agroindustria ha sido considerada y estimulada como una forma de solucionar algunos de los problemas económicos y sociales del agro, ya que conlleva innovaciones técnicas y modernización del proceso productivo, estandarización de los productos agrícolas, fomenta la producción de cultivos no tradicionales, introduce mejoras en la comercialización y distribución de alimentos en estado primario y procesados, asegura mercados y estabiliza precios e ingresos a los agricultores.

La amplitud de las ramas que componen la agroindustria latinoamericana, el dinamismo y diversificación de la producción, los distintos tamaños de las agroindustrias, las diferencias de tecnología y la variedad de su procedencia, la falta de información estadística actualizada, son causas que dificultan un análisis detallado de la evolución regional de esta heterogéneà y compleja actividad productiva. De todos modos, el estudio de casos supera los límites de este trabajo.

El sector alimentario es el más importante de la agroindustria regional. Las ramas alimentarias vinculadas con la refinación de azúcar y con los productos de molinería son, por lo general, de lento crecimiento puesto que tants el

\footnotetext{
${ }^{30}$ Eslabones hacia atrás, vinculados con la producción de insumos para la agricultura; y eslabones hacia adelante, relacionados con el procesamiento de insumos provenientes de la agricultura en sus distintas fases de transfonnación.
}

azúcar como el trigo son productos cuya demanda se expande lentamente y, por lo general, fueron sometidos a algún tipo de medidas de fijación de precios al consumidor. La industria alimentaria secundaria - pastas, fideos y otros alimentos preparados derivados del trigo-crece con mayor dinamismo debido a la continua expansión de su demanda urbana y rural. La elaboración de aceites y grasas vegetales, los preparados de cacao y café, como asi los productos de confitería muestran tasas elevadas; se orientan a mercados internos y extemos en expansión. Crecen moderadamente -en algunos países lo hacen con rápidez- las ramas vinculadas a la matanza de ganado, preparación y conservación de cames, elaboración de productos lácteos, envasado y conservación de frutas y legumbres dadas las condiciones de competencia con productos importados que enfrentan habitualmente. En general, las ramas que producen bienes de consumo popular tienden a crecer más lentamente que las que producen alimentos elaborados destinados a estratos de ingresos medios a altos.

En su expansión, la agroindustria se apoya en el sector empresarial agrícola, cuyas características organizativas y productivas facilitan la articulación de sus producciones con las actividades del agronegocio. Este, de otro lado, orienta su producción hacia los consumidores urbanos de ingresos medios y altos y hacia los consumidores rurales con ingreso suficiente como para que puedan adquirir sus productos. Por lo tanto, la agroindustria deja de lado la agricultura campesina -con pocas excepciones, resultantes éstas de su agrupación en cooperativas-y a los consumidores urbanos y rurales muy pobres y que por lo tanto no están en condiciones de comprar productos alimenticios con alto valor agregado. 
Los diagnósticos nacionales coinciden respecto al evidente crecimiento de sus agroindustrias; y también registran incrementos en el número de empresas transnacionales dentro de la agroindustria local. Muchas de esas corporaciones tienen importancia mundial por el volumen de sus ventas anuales y por sus ramificaciones. En general, están verticalmente integradas y diversificadas, características tanto más evidentes cuanto mayor es su importancia.

Las empresas transnacionales se implantan en las ramas más importantes del sistema agroindustrial nacional y constituyen núcleos dominantes y de concentración de capital, que orientan la mayor parte de su producción al mercado interno; es reducida su participación. en el comercio exterior de productos procesa- dos y generan una cierta especialización productiva por razones de clima, suelos, tenencia de la tierra, infraestructura y facilidades de acceso a los grandes mercados urbanos nacionales. ${ }^{31}$

La inversión privada extranjera financia, con preferencia, la producción de alimentos elaborados y de insumos tecnológicos básicos para el proceso productivo, como así para su mercadeo. Sustituye el capital nacional en la instalación de unidades productivas que se articulan, en las condiciones más favorables, a procesos de sustitución de importaciones o de fomento de las exportaciones, basados principalmente en la explotación de los recursos naturales.

Las unidades productivas agroindustriales transnacionales instaladas en América Latina, crecieron de modo distinto. Una proporción muy importante de sus ampliaciones y diversificaciones fue consecuencia de la compra y absorción de empresas nacionales en funcionamiento y de su fusión con otras nuevas, ahorrando así parte de los gastos de instalación y

${ }^{31}$ CEPAL, "Las empresas transhasionales en la agro industria mexicana" (CEPAL/MEX/1049), mayo de $198 \mathrm{l}$. acentuando la concentración. Esto les ha permitido adquirir mayores tamaños y redes adicionales de filiales, adoptar y seleccionar una gran diversidad de tecnologías, utilizar personal calificado y robustecer su capacidad operativa y su presencia en los mercados.

De antiguo es la vinculación de las empresas transnacionales y de otros inversionistas privados extranjeros con la agricultura latinoamericana. Han incursionado en la explotación del suelo, han aprovechado la mano de obra barata y controlado la elaboración y comercialización de muchos productos: frutas y vegetales, azúcar, algodón, cacao, carne, lácteos, pesca, aceites comestibles, trigo, tabaco, madera, cuero, bebidas no alcohólicas y confitería, bebidas alcohólicas y bebidas tropicales. Progresivamente fueron interviniendo en nuevas ramas: a la producción de alimentos elaborados básicos añadieron la de alimentos orientados a mercados urbanos de altos ingresos y vendidos en cadenas de supermercados o restaurantes (alimentos 'sofisticados' a base de carnes y leche, platos preparados, confitería fina, etc.). Además sustentan la producción a contrata de frutas frescas, legumbres, hortalizas y flores destinadas a mercados de países desarrollados.

La inversión extranjera en la agroindustria latinoamericana —entendida en su acepción más amplia- es de larga data. Sin embargo, en la década de los años setenta fue quizás más intensa que en el pasado, en particular en las ramas de maquinaria agrícola, productos agroquímicos -fertilizantes, insecticidas, fungicidas, herbicidas $-\mathrm{y}$ productos veterinarios. Prácticamente todas las empresas transnacionales que operan en estos renglones se han establecido en los países latinoamericanos, bien sea como fabricantes o como representaciones comerciales, de modo que penetran $y$, por lo general, dominan los mercados nacionales e influyen decididamente en su evolución y características. 


\section{Conclusiones}

Cada uno de los tópicos analizados posibilitaría conclusiones especificas. Sin embargo, nos parece que las más relevantes surgen al contrastar la expansión productiva y las transformaciones registradas durante la década pasada, con el logro de los objetivos básicos perseguidos por la sociedad y económía latinoamericanas: la eliminación del hambre y de las carencias nutricionales, y la erradicación de la pobreza y situaciones de indigencia. Cabe contrastarlos, además, con la consecución de dos propósitos complementarios: la expansión de las exportaciones agrícolas y evitar que la búsqueda de la eficiencia económica a corto plazo, altere los ecosistemas y deteriore amplias extensiones de tierras.

La expansión productiva destinada al mercado interno ha respondido simplemente a los estímulos y movimientos de la demanda resultantes, ambos, del aumento de la población urbana y de los cambios producidos en los regímenes alimentarios de los distintos estratos de ingreso. Por ello, el incremento de la producción tuvo efectos ambivalentes en lo nutritivo. De un lado, ha contribuido a una mayor disponibilidad media de alimentos de alto valor nutritivo, Ios que fueron adquiridos por consumidores de ingresos medios y altos; $y$, por otra parte, para el consumo popular ha suministrado de modo creciente alimentos que aportan calorías vacías -azúcar, aceites, tubérculos-y, en forma decreciente, aquellos otros que contienen nutrientes equilibrados -cereales y leguminosas-, esto debe haber conducido al agravamiento de las carencias nutricionales de los grupos más pobres. En consecuencia, los resultados del proceso productivo no estuvieron orientados a la eliminación del hambre y la malnutrición, en su sentido estricto.

El alza de los precios reales de los alimentos respecto a sus niveles de comienzo de los años setenta, influyó en la acentuación de los problemas alimentarios. La intensidad de los procesos inflacionarios, entre otras secuelas, empeoró el estado nutricional de los desprotegidos, forzados a modificar su régimen alimentario e ingerir alimentos baratos, de escaso va- lor nutritivo, pero que dan la sensación de plenitud gástrica.

En lo que respecta a la erradicación de la pobreza rural, la expansión productiva lograda, si bien importante, está todavía lejos de la requerida para contar con la base material necesaria para que el ingreso medio agrícola acorte distancias y se aproxime al ingreso medio de toda la economía. Una más acelerada expansión productiva agrícola, que llegue a mediano plazo a duplicar o triplicar las dimensiones actuales de la agricultura, es condición necesaria, pero no suficiente, para erradicar la pobreza rural. Se necesita la aplicación complementaria de medidas de carácter distributivo o redistributivo - según sean las peculiaridades de cada país - para que los resultados del proceso productivo alcancen en forma más equitativa a los diferentes estratos de la población.

El desarrollo de las fuerzas productivas agrícolas no ha contribuido a diluir la contradicción más notoria de la agricultura latinoamericana: la existencia simultánea de tierras abundantes, no aprovechadas plenamente, y un númeto creciente de familias campesinas subocupadas. Por el contrario, y debido a las transformaciones ocurridas en el interior de sus dos componentes principales, los empresarios y el campesinado, ese desequilibrio secular estaría acentuándose. En esa polarización han influido, desde luego, las estrategias seguidas por ambos sectores: los empresarios, para sacar mayores beneficios en su favor y los campesinos para enfrentar y adaptarse a situaciones cambiantes y defender o elevar su nivel de vida. Las migraciones permanentes o temporales hacia el medio urbano-industrial y hacia áreas de colonización donde pueden constituir nuevas unidades familiares, forman parte del modo en que el campesinado enfrenta el subempleo y asegura un nivel mínimo de ingresos.

Si bien la situación agraria de muchos países de la región difiere de la predominante dos décadas atrás -hubo progresos de distinto grado-, la necesidad de continuar modificando las condiciones de acceso a la tierra sigue conservando importancia estratégica, a efectos de 
ampliar resultados exitosos de acciones de reforma agraria antes emprendidas $y$ también como un medio importante para alcanzar los propósitos que persiguen las estrategias de superación de desequilibrios estructurales y el logro del desarrollo armónico de la sociedad.

La progresiva concentración tanto de la producción y del ingreso agrícolas como de las oportunidades derivadas de los mercados $\longrightarrow$ de productos, de factores y financieros- resultantes tanto de las caracteristicas del sector empresarial como de las políticas públicas que más los benefician junto a las implicaciones de su creciente articulación con el agronegocio, son realidades distintas de las que presentó en el pasado el agro latinoamericano y que tuvieron como base de sustentación al complejo latifundio-minifundio. La pujanza del empresariado, articulado funcionalmente a la continua descomposición-recomposición del campesinado es una realidad aún no entendida satisfactoriamente ni valorada en sus verdaderos alcances $y$ repercusiones.

La capacidad de los grupos pobres de mejorar sus ingresos está estrechamente ligada a la calidad y cantidad del trabajo y a la percepción de una remuneración justa por su esfuerzo productivo. El trabajo, a su vez, depende de las condiciones de acceso a los recursos productivos, en particular a la tierra. La búsqueda más intensa de amplias y renovadas oportunidades de empleo para la población rural fue y será elemento importante en la lucha para vencer la pobreza rural. Los más variados caminos, según las realidades nacionales y locales, podrían utilizarse para facilitar un mayor acceso a la tierra.

Parte importante de las medidas de acceso a la tierra ha sido la ocupación del territorio nacional, vinculada a la ampliación de la frontera agrícola. Formas más o menos exitosas de colonización y de apertura de tierras al riego aliviaron la presión demográfica típica de determinadas zonas de pobreza rural, al mismo tiempo que contribuyeron a la expansión productiva y a la generación de nuevos empleos.

Las políticas orientadas a abaratar el capital e incentivar el uso de insumos técnicos en el proceso productivo agrícola han incidido negativamente scbre el empleo agrícola. Tuvieron como propósito la formación de capital en las fincas y la tecnificación de las labores de culti- vo, pero han llevado a reducir el papel que desempeña la fuerza de trabajo, recurso abundante en la función agregada de producción. De otro lado, y en ciertos casos, regulaciones introducidas en los mercados de trabajo han encarecido el costo de la mano de obra y estimulado que se tienda a prescindir de la fuerza de trabajo permanente y a utilizar mano de obra temporal en escala creciente.

Los programas de desarrollo rural integrado o integral han aparecido como formas de concentrat recursos en favor del campesinado, de favorecer su incorporación a los mercados, hacerlos permeables al progreso técnico y dotarlos de servicios gubernamentales de apoyo y asistencia que contribuyan a mejorar sus condiciones de vida y trabajo. Sin embargo, puesto que la naturaleza de esos programas no se compadece con las rafces de la pobreza rural, sus resultados no llegaron más allá de los límites restringidos de sus propias acciones que no pretendian facilitar el acceso a los recursos productivos.

Por falta o escasez de innovaciones tecnológicas concebidas como respuesta a las condiciones económicas y sociales de la gran masa de productores de cada país, la disponibilidad de tecnologia predominante es la que ofrecen los mercados intemacionales, lo que muchas veces ha contribuido a la adopción de patrones tecnológicos sesgados respecto a las exigencias nacionales de un desarrollo agrícola equilibrado. A pesar del avance logrado en América Latina en la organización de la investigación y en la formación de investigaciones persiste, en general, un desconocimiento de las necesidades del campesinado y de experimentos que presten debida atención a la forma particular en que éste organiza su actividad económica y utiliza el suelo. Faltan investigaciones sobre cultivos importantes para la agricultura campesina y sobre sistemas productivos basados en cultivos asociados o múltiples.

La modalidad dominante de desarrollo tiende a incrementar el grado de apertura de las economías y al acrecentamiento de la interdependencia entre naciones. El intercambio agricola de los países latinoamericanos con el resto del mundo refleja esas tendencias. Tuvo lugar una diversificación de las exportaciones y por lo tanto una mayor articulación de las agricultu- 
ras nacionales con la demanda externa. Del lado de las importaciones, si bien éstas no se han diversificado mucho, ha aumentado la dependencia y con ello la vulnerabilidad del abastecimiento de alimentos frente a cambios inesperados en las condiciones de los mercados mundiales, tanto en materia de seguridad en los suministros, como en variaciones en los precios. Adquirió mayor trascendencia lo relativo a capacidad efectiva de almacenamiento en puertos, disponibilidad y eficiencia de los medios de transporte y grado de la fluctuación en los fletes.

El ambiente de inestabilidad e inseguridad característicos de los mercados agrícolas internacionales, ha influido fuertemente sobre la evolución de las agriculturas nacionales que dependen de las exportaciones y por extensión, ha provocado perturbaciones de diverso grado en el desenvolvimiento de las economías nacionales. De otro lado, los altos niveles del proteccionismo han menoscabado las oportunidades de los países de la región que producen en condiciones favorables y pueden, por lo tanto, ser muy competitivos en algunos de los mercados mundiales agrícolas.

Para la región en su conjunto--lo que no se aplica a países en particular- entre 1969-1971 y 1977-1979 el valor en dólares corrientes de las importaciones creció más rápidamente que el de las exportaciones; lo hicieron al 18.7 y $16.5 \%$ por año, respectivamente. Estos ritmos son menos distantes entre sí de los que corresponden a los de los volúmenes, los que - como ya se indicó- fueron del 8.0 y $2.8 \%$ anual, respectivamente. El alza agregada de los precios de los productos agrícolas exportados explica que las exportaciones hayan tenido un mejor comportamiento del previsto y que hayan contribuido de mejor modo al saneamiento o a la atenuacion de los déficit de los balances comerciales.

Las políticas tecnológicas adoptadas estuvieron en mayor o menor medida intluidas por el modelo tecnológico creado por la llamada 'revolución verde'. Sin desconocer los notables avances científicos logrados desde entonces y traducidos en complejos paquetes tecnológi$\cos$, que han facilitado la expansión de la frontera agrícola y una todavia modesta elevación de los rendimientos unitarios medios, se percibe la ausencia de iniciativas tecnológicas que no tiendan a la homogeneización de los ecosistemas y, por ende, a la alteración y/o pérdida de sus atributos. La búsqueda de la eficiencia económica a corto plazo ha provocado en América Latina la inutilización de amplias extensiones de tierras, particularmente en áreas tropicales. Tampoco hay progresos notorios en materia de recuperación de zonas ecológicamente degradadas, ni en lo relativo a la implantación de agrosistemas menos dependientes del consumo de energía fósil.

Un abigarrado conjunto de causas y factores ha interactuado y determinado de modo combinado las transformaciones ocurridas en la sociedad rural latinoamericana y ha estimulado la mayor diferenciación económica y socíal que hoy se advierte en la agricultura regional Dentro de ese complejo conjunto, resaltan las nuevas estructuras urbanas e industriales y las consiguientes modificaciones, en sentido y profundidad, de las relaciones urbano-rurales; la penetración diferenciada del progreso técnico y el apego a la eficiencia y rentabilidad que le acompaña; las decisiones de política de abaratar el capital y los medios técnicos requeridos por el proceso productivo y la consecuente formación acelerada de capital en las unidades empresariales y el patrón de maquinización y acrecentado uso de insumos tecnológicos que la acompaña; la influencia selectiva y a veces distorsionante del sector externo; el dinamismo del agro-negocio asociado a las corporaciones transnacionales, la realización de importantes obras de infraestructura física y de comunicaciones; la revisión y puesta al día en cuanto a propósitos, medios de acción y clientela de diversos programas y acciones gubernamentales en favor de la agricultura; los resultados - todavía no conocidos ni valorados acabadamente- de los procesos y acciones de reforma agraria y los cambios en los sistemas de tenencia de la tierra; las modificaciones introducidas en las relaciones laborales y las transferencias intersectoriales -temporales o a más largo plazo - favorables a la agricultura. A esta larga mención se añaden otros factores de menor importancia aparente.

Numerosas y complejas son pues las causas y factores que deben ser considerados individual y simultáneamente, para lograr que se den las condiciones para que la agricultura pueda 
desempeñar plenamente sus funciones esenciales y manifieste con pujanza su verdadero potencial. De igual modo, numerosas deben ser las medidas y acciones que es preciso tomar y emprender, para que la agricultura pueda contribuir apropiadamente al desarrollo global y simultáneamente supere sus propios problemas. Causas complejas y difíciles, por el núme- ro de sus componentes y por las relaciones entre componentes, no pueden ser enfrentadas y superadas con soluciones sencillas. El gran desatío para la agricultura latinoamericana consiste en conciliar la eficiencia técnica y económica con el apremiante mejoramiento social, y, al mismo tiempo, constituir un sector dinámico y estable para la economía global. 